INSIGHTS FOR RURAL HEALTH CARE PROVIDER

RETENTION: A QUANTITATIVE SURVEY ANALYSIS

\author{
A thesis presented to \\ the Faculty of the Graduate School \\ at the University of Missouri-Columbia \\ In Partial Fulfillment \\ of the Requirements for the Degree \\ Master of Science
}

By

MARIA KUHNS

Dr. Sarah Low, Thesis Supervisor

MAY 2021 
The undersigned, appointed by the dean of the Graduate School, have examined the thesis entitled

\section{INSIGHTS FOR RURAL HEALTH CARE PROVIDER \\ RETENTION: A QUANTITATIVE SURVEY ANALYSIS}

presented by Maria Kuhns,

a candidate for the degree of Master of Science

and hereby certify that, in their opinion, it is worthy of acceptance.

Sarah Low, Ph.D.

Theodoros Skevas, Ph.D.

Kathleen Quinn, Ph.D.

John Pender, Ph.D. 


\section{ACKNOWLEDGEMENTS}

I have been incredibly fortunate to have an incredible support system who mentored, assisted, and served as confidants during the thesis writing process. Many thanks to my advisor and incredible mentor, Dr. Sarah Low for taking me on as a graduate student despite my lack of econometric and calculus knowledge. Your mentorship, warmth, and honesty have developed my research, writing and professional skills immensely. Thank you to Dr. John Pender for taking me on as an intern at the Economic Research Service and teaching me so much about econometric methods and drafting reports. I am so thankful for the time you have invested in me through virtual meetings, reviews of my work, and emails explaining various statistical challenges. It's been an honor to be mentored by such an excellent researcher and economist. To Dr. Kathleen Quinn, thank you for the encouraging emails and discussions and believing in my potential. The opportunities you have given me are second to none, and you have been a source of warmth throughout the process. Dr. Theo Skevas, thank you for providing statistical expertise and encouragement.

Thank you to the Exceed team, Dr. Mallory Rahe, Alan Spell, Hannah McClure, Catherine Isley, Austin Sanders, and Charlie Dake for making my assistantships one of the coolest jobs I've ever had and teaching me so much over the past two years.

Many thanks to my life partner, Zach Callow, for supporting me in everything I do and keeping me true to who I am. You have been my biggest champion and have given me confidence went I felt like an imposter. Thank you to my parents, Stan and Shelly Kuhns, for instilling in me a passion for learning and rural places and for giving me the strength to pursue higher education. Because of the both of you, I find myself where I am today. Special thanks to my mom, Shelly Kuhns, for providing so much insight into the challenges of rural health care and for instilling a passion in me for health equity. Lastly, thank you to Jaime Luke, Alex Stichnote, and Kate Preston for being my grad student support group throughout the past two years. Our evening debriefs and vent sessions have been invaluable. 


\section{TABLE OF CONTENTS}

ACKNOWLEDGEMENTS.

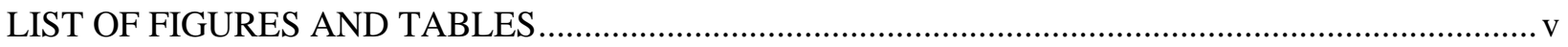

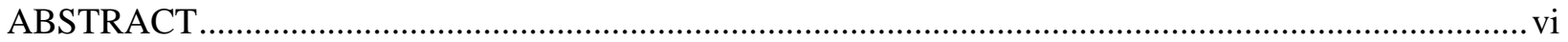

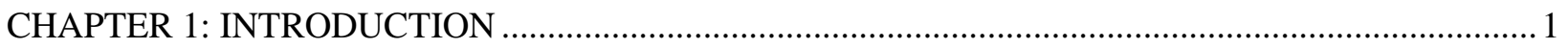

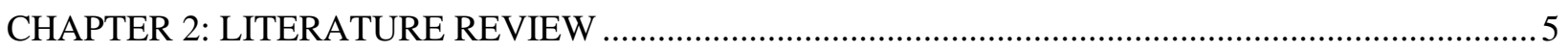

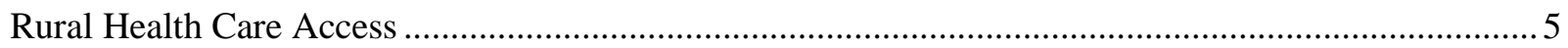

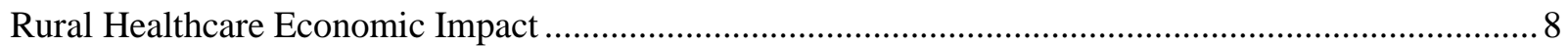

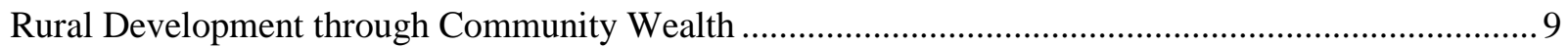

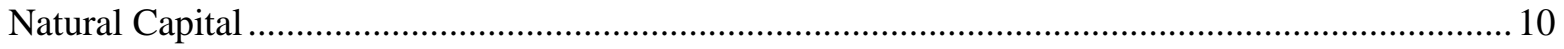

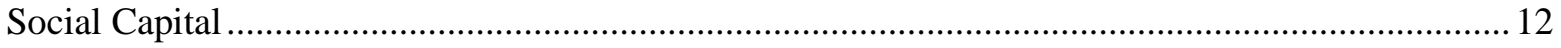

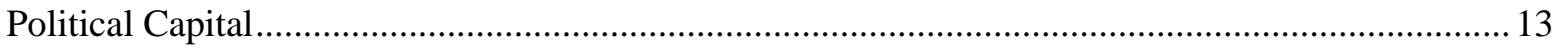

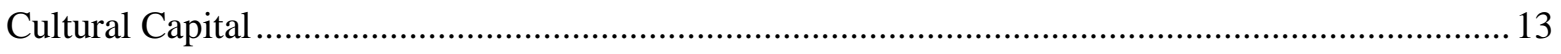

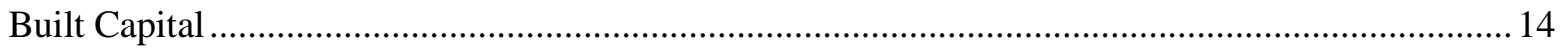

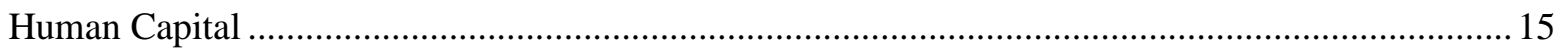

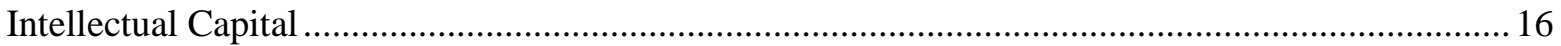

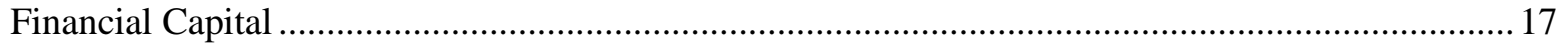

Health Care Provider Retention Literature …............................................................................... 18

Provider Demographic and Background Characteristics ........................................................... 19

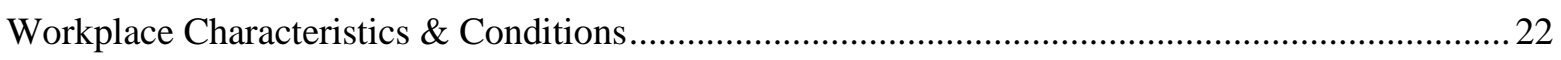

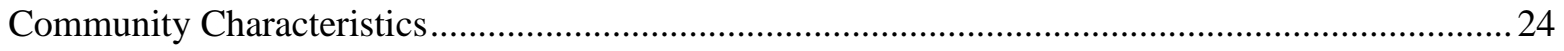

CHAPTER 3: SURVEY ON RURAL COMMUNITY WEALTH AND HEALTH CARE PROVISION 27 


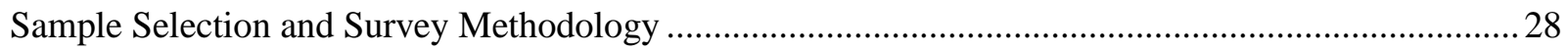

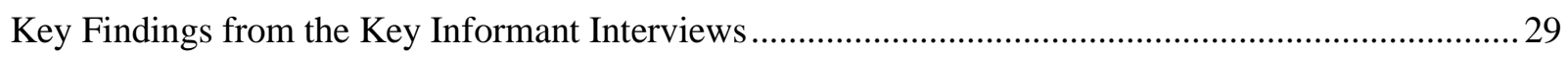

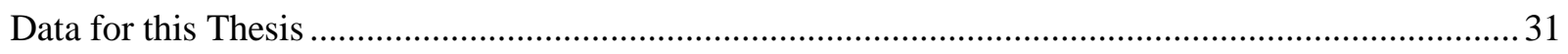

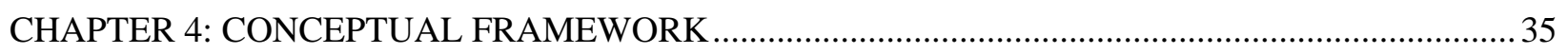

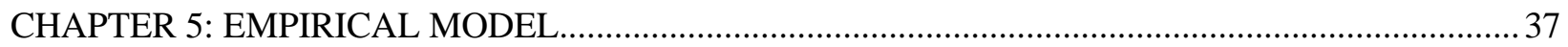

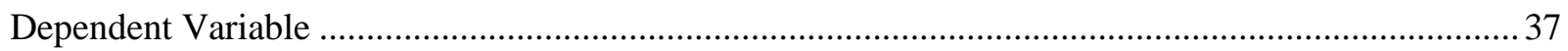

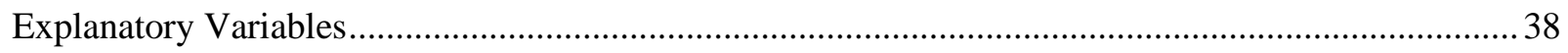

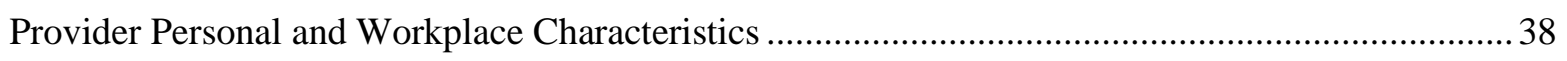

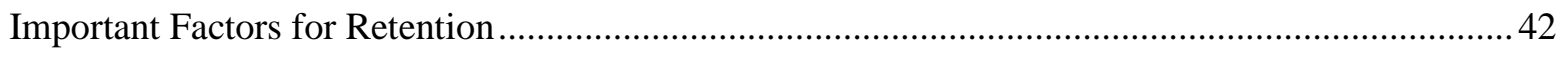

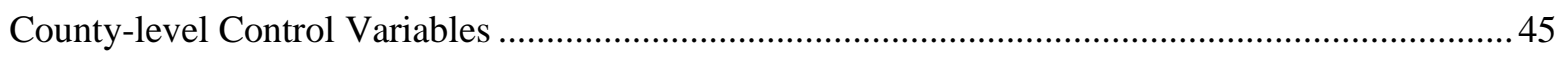

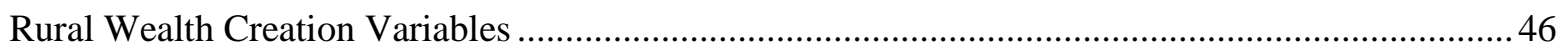

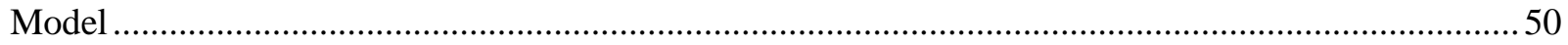

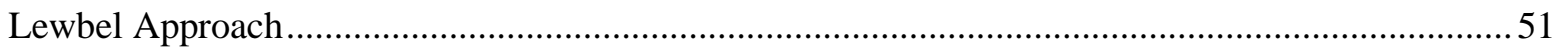

Standard Error Estimation and Survey Weights ....................................................................5

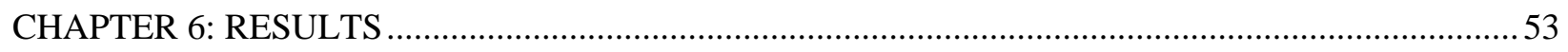

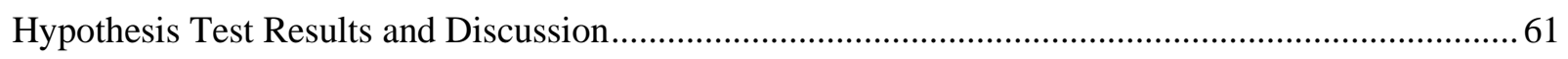

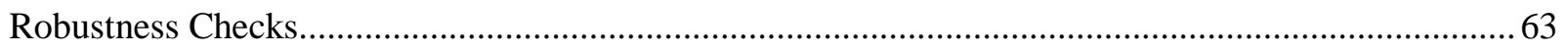

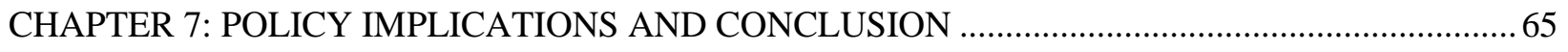

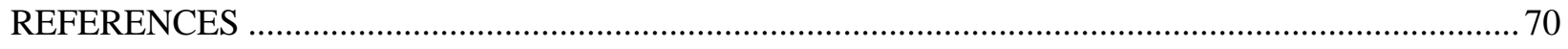

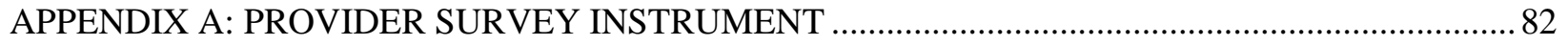

APPENDIX B: COMPLETE REGRESSION RESULTS FOR ALL FIVE MODELS ...........................95 


\section{LIST OF FIGURES AND TABLES}

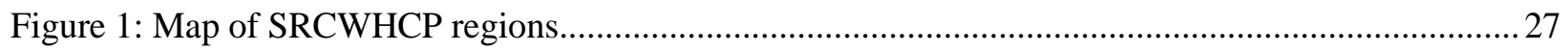

Table 1: Survey response outcomes by region (after incentives) ...................................................... 31

Table 2: Survey response outcomes by provider type (after incentives) ............................................... 32

Table 3: Survey Responses by Provider Type and Region ............................................................... 32

Table 4: Survey respondent demographic and familial characteristics................................................ 34

Table 5: Provider personal and workplace characteristic variables taken from the survey ....................... 38

Table 6: How important to you are each of the following reasons for continuing to work in this

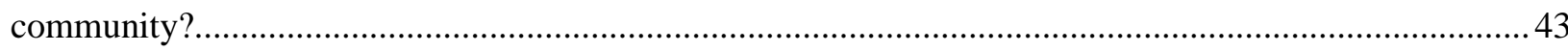

Figure 2: Factors cited as "important" or "very important" by providers in their decision to continue

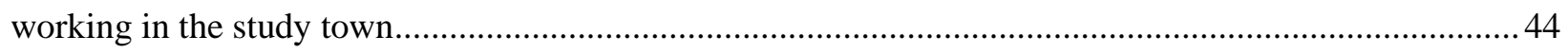

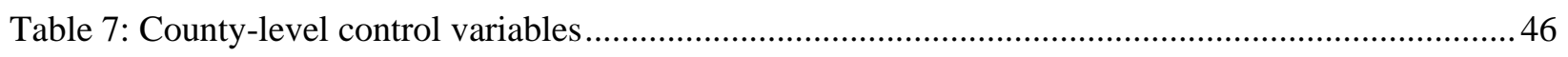

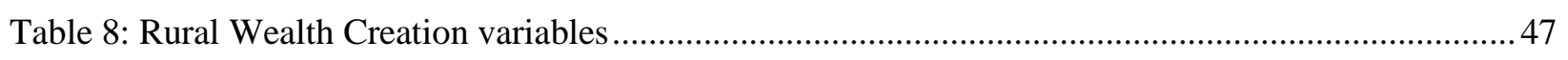

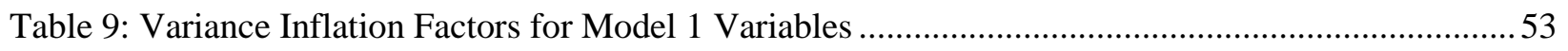

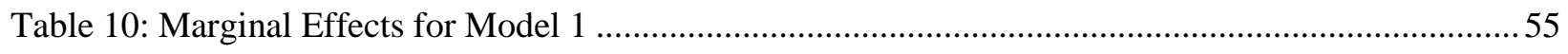

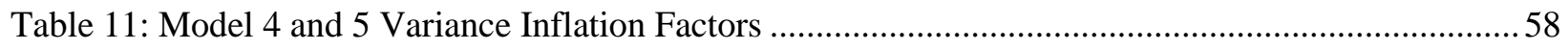

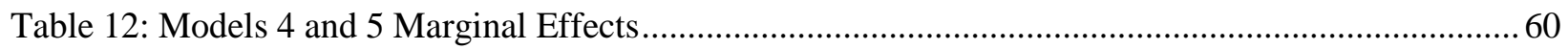

Table 13: Model 1 (Base model) Coefficients and Marginal Effects .................................................... 95

Table 14: Model 2 Coefficients and Marginal Effects.........................................................................96

Table 15: Model 3 Coefficients and Marginal Effects ......................................................................... 97

Table 16: Model 4 (restricted model) Coefficients and Marginal Effects ..............................................98

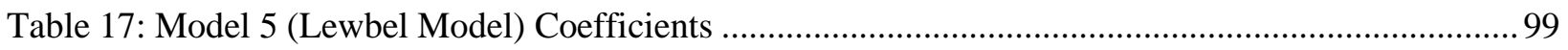




\begin{abstract}
Due to rural health disparities and an uneven distribution of health providers across the rural urban continuum, retaining the existing rural health care provider workforce may be an important strategy to maintain existing rural health care provision. While a large body of literature addresses how to recruit health care providers to rural areas, less is known about how to retain these providers. Even less literature has focused on the role of rural communities in health care provider retention.
\end{abstract}

In this thesis, I examine the role of provider background and familial characteristics, workplace characteristics, and community characteristics that may impact a provider's likelihood to consider leaving a rural community. I use data from a survey of over 900 rural health care providers across nine states and a probit model to estimate the impact of these characteristics on a provider's propensity to consider leaving.

I find that establishing social ties and integrating within the community through volunteering reduces providers' likelihood to consider leaving by 10 percent. Additionally, providers who engage in entrepreneurship by investing in part or all of their practice are 12 percent less likely to consider leaving, all else being equal. I also find that having unacceptable on-call responsibilities increases a provider's likelihood to consider leaving by 17 percent.

This thesis contributes to the existing literature by estimating the effects of work-life balance, entrepreneurship, and the role of family and personal integration on provider retention. Furthermore, it emphasizes the role of communities in provider retention. These results offer insights to rural communities and decision-makers seeking to identify how to maintain their existing rural health care workforce. 


\section{CHAPTER 1: INTRODUCTION}

Perhaps one of the best and most recent illustrations of the importance of health care provision is the 2020 COVID-19 pandemic. Across the world, governments and communities felt the importance of access to health care. Within the United States, variation across the rural-urban continuum amplified the effects of COVID-19. USDA Economic Research Service found rural residents were more vulnerable to severe illness or death from COVID-19 than their urban counterparts (Dobis and McGranahan, 2021). This vulnerability stemmed from a difference in demographics including a larger share of rural residents with an underlying health condition, more of the population lacking health insurance, a disproportionately older adult population, and further average distance to an intensive care hospital. All of these differences existed prior to the pandemic and will not go away when the pandemic subsides.

With rural areas already struggling to maintain health outcomes that match those of urban areas, it is important to maintain the existing rural healthcare workforce. More generally across the rural-urban continuum, the U.S. Department of Health and Human Services projects a shortage of over 20,000 primary care practitioners by 2025 . These shortages are not distributed evenly across the United States, with the South and the Midwest experiencing continual health care provider shortages (Palmer, 2020). Programs like the National Health Service Corps (NHSC) attempt to address the need for providers in areas with health care provider shortages by incentivizing providers to practice in underserved areas, but long-term retention of these providers remains a challenge. Only 35 percent of primary care providers remain in the communities they were initially assigned to six years after completing their NHSC obligation (Negrusa \& Taplin, 2016).

The shortage is likely to be more acute in rural areas. The rate of primary care physicians per 100,000 residents grew from 76 to 80 in urban areas between 2010 and 2018, and declined from 55 to 52 primary care physicians in rural areas (HRSA Area Health Resource Files, 2020). In 2012 alone, Hing and Hsiao (2014) found an uneven supply of primary care physicians across metropolitan status with 39.8 physicians per 100,000 people in rural areas compared to 53.3 physicians were 100,000 in metropolitan 
areas in 2012. A better understanding of what motivates providers to remain in communities is needed to address rural health care provision needs.

In this thesis, I investigate what actions taken by rural health care workplaces and rural communities can promote rural health care provider retention. Specifically, I seek to accomplish three things: 1) to understand how social capital in a community can aid in providers' satisfaction with place of work, 2) to understand how workplace conditions impact providers' willingness to consider leaving, and 3) to provide a preliminary assessment of how entrepreneurship can positively impact provider retention. I utilize a confidential survey dataset from the United States Department of Agriculture's Economic Research Service (USDA ERS) that includes 928 rural health care providers in nine states across the United States.

My analysis draws on two disparate bodies of literature - literature surrounding strategies for rural healthcare provider retention and the Rural Wealth Creation literature. The Rural Wealth Creation framework was conceptualized by Pender et al. in a 2014 book as a method for assessing community assets as forms of wealth to be utilized when working to achieve sustainable rural economic development. Pender et al. (2014) divides rural assets, or capitals, into eight categories - natural, social, political, cultural, built, human, intellectual, and financial capital. Due to the recent conceptualization of Rural Wealth Creation, scarce literature exists that applies the framework to economic outcomes. No literature exists that applies it to health care provider retention, or even more broadly retention of any highly trained professionals. However, the importance of various community capitals can be identified in the existing provider retention literature, largely through the repeat emphasis on the importance of providers integration and involvement in both the professional community and the community at large in which they live (Conte et al., 1992; Cutchin, 1997; Mayo and Matthew, 2006; Henry and Hooker, 2007; Stenger et al., 2008; Hancock et al., 2009; Cameron et al., 2010; Chipp et al., 2011).

My analysis is unique in three facets - access to unique data, emphasis on the role of the community, and a large sample size. My analysis uses data from the 2015 USDA ERS Survey on Rural 
Community Wealth and Health Care Provision (SRCWHCP). The SRCWHCP sought to better understand the role rural communities play in recruitment and retention of health care providers. Prior to this thesis, no multivariate analyses of the survey data had been conducted and the only work generated from the data is a USDA ERS report currently under review. Furthermore, in prior works, the analyses have often been limited to qualitative approaches or univariate analysis due to small sample sizes. The SRCWHCP not only contains a large number of provider responses, the responses are scattered across rural communities in nine states. Lastly, when the SRCWHCP was written, the instrument placed special emphasis on gathering information on the role of the community in provider satisfaction. To further understand the role of community characteristics in provider retention, I also incorporate secondary data to assess the effect of community assets on retention. Because of this emphasis, my analysis takes a special look at how communities can take action in working to retain health care providers.

To first establish the importance of this thesis and the issues facing rural health care, I begin Chapter 2 with a review of the literature surrounding rural health care access and the role of health care in the rural economy. I then introduce the concepts of Rural Wealth Creation, namely the various community capitals and how they can positively impact rural communities. I follow with a review of the existing rural health care provider retention literature with an emphasis on tying the findings to the various community capitals.

In Chapter 3, I introduce the Survey on Rural Community Wealth and Health Care Provision more broadly and summarize some of the initial findings from the survey analysis. I introduce the overarching goals of the survey and how the survey sample was collected. I spend time briefly covering the survey methodology. I then describe in more detail the data from the survey used for this thesis.

Chapter 4 establishes my three hypotheses related to the relationship between retention and three factors: social capital, workplace characteristics, and entrepreneurship. I then turn to my empirical model in Chapter 5 to explain how I empirically test my hypothesis. I explain the proxies I have chosen to 
represent various factors in provider retention. I discuss the potential for endogeneity due to incorporating related survey questions in my models and I present a potential solution.

In Chapter 5, I present my results across three models. My first base model uses only information taken from the provider survey, while my final two models incorporate secondary data and sentiments regarding retention from the providers. I present various robustness checks that strengthen my results. I identify that my results reinforce the importance of establishing personal connections and forming relationships within the community where a provider chooses to work. I identify how lack of work-life balance, stress, and isolation may have a negative impact on long-term provider retention, and I present entrepreneurship as an opportunity to promote retention for rural health care providers.

In Chapter 6, I close by discussing the implications of the results for policy makers and rural communities, limitations and future directions for research. I explain how my analysis is limited due to challenges of endogeneity and lacking heterogeneity across place. Finally, I identify how my analysis contributes to the body of research focused on promoting health care providers choosing rural areas, and more importantly, remaining in rural areas. 


\section{CHAPTER 2: LITERATURE REVIEW}

\section{Rural Health Care Access}

To better understand the relationship between health care provision and rural economic

development, the USDA Economic Research Service conducted a nine-state regional survey of healthcare providers and community members in 2015 . Over 900 rural health care providers completed surveys and more than 300 non-provider key informants completed phone interviews regarding questions on how rural community assets affect recruitment and retention of health care providers and the impact of health care provision on community economic development. The key informants who responded to phone interviews included mayors and elected community leaders, economic development organization leaders, educators, and healthcare facility and health department administrators. When asked about the most important health care issue facing their town, the most common response among key informants was a lack of health care providers, followed closely by the aging population within their communities.

Concerns regarding the shortage of health care providers and a growing aging population are not siloed to the 150 communities in the ERS study. The shortage of primary care providers has received national attention. In 2016, the U.S. Department of Health and Human Services projected a shortage of over 20,000 primary care practitioners by 2025 (U.S. HRSA Bureau of Health Workforce, 2016). Despite the provider shortage, healthcare quality and access at the national level has improved following the implementation of the Affordable Care Act and Medicaid expansion, but healthcare access disparities still exist for poorer and non-White populations (National Healthcare Quality and Disparities Report, 2016), and vary across regions and the rural-urban continuum. According to the American Association of Medical Colleges, the South and the Midwest experience continual shortages, while the West's supply of providers meets demand and the Northeast has provider surpluses (Palmer, 2020).

One of the largest attempts to address the aforementioned challenges was by incentivizing health care providers to locate underserved areas. In 1972, the Health Resources and Services Administration created the National Health Service Corps (NHSC) to strengthen and grow the U.S. primary care 
workforce in areas with limited access to care. The NHSC program provides loan repayment for medical practitioners who agree to serve in Health Professional Shortage Areas (HPSAs) (U.S. Health Resources $\&$ Services Administration, 2020). A HPSA is a designation that indicates provider shortages in primary care, dental health, or mental health. Despite continual efforts to improve limited health care access in rural places, 61 percent of Primary Care HPSAs, 59 percent of Mental Health HPSAs, and 63 percent of Dental HPSAs are in in rural places (U.S. HHS Bureau of Health Workforce, 2020).

Lack of healthcare facilities further intensifies the healthcare provider shortage. Over 80 percent of counties without a clinic, medical center, rural health clinic, or hospital were nonmetro counties (Cromartie et al., 2020). Continual closures of rural hospitals exacerbate this issue. Rural hospitals have been closing over the past 15 years due to financial challenges stemming from population loss and loss of revenue due to bypass behavior (Thomas et al., 2016). The University of North Carolina Cecil G. Sheps Center for Health Services Research has maintained an active list of rural hospital closures in the United States since January 2005 - they record 180 rural hospital closures with 136 occurring between 2009 and 2021. In Missouri, seven hospitals closed between 2014 and 2020 (UNC Sheps Center, 2021). Hospital closures have garnered national media attention - in July 2018, the New York Times published a piece highlighting challenges faced by a 21-year-old pregnant mother from Kennett, Missouri who traveled nearly 100 miles to the nearest hospital after beginning premature labor contractions.

As shown by the New York Times article, shortages in both providers and facilities creates potential for poor health outcomes. Using the 2013 County Health Rankings and Roadmaps data developed by the University of Wisconsin and the Robert Wood Johnson Foundation, Anderson et al. (2015) found that rural U.S. county residents are more likely to experience premature deaths and poorer overall health than their urban counterparts. Rural counties scored significantly lower in health behaviors including substance use and diet and exercise and in clinical care attributes including preventable hospital stays, diabetic and mammography screenings, access to primary care physicians and dentists, and size of uninsured population. Other studies have targeted specific risk factors associated with rurality - rural 
people are more often obese (Henderson \& Low, 2006; Befort et al., 2012), are more likely to use tobacco products (Wiggins et al., 2020; Roberts et al, 2016; Lutfiyya et al., 2008) and are more likely to commit suicide (Ivey-Stephenson et al., 2017; Singh \& Siahpush, 2002). Moreover, these health outcomes are coupled with a rise in drug abuse. From 1999 to 2017, the age-adjusted rate of drug overdose deaths in rural counties increased from 4.0 to 20.0 per 100,000 people (Hedegaard et al., 2019).

Population age dynamics and prevalence of disabilities also play a role in health care needs for rural areas. Zhao et al. (2019) found that rural adults were 9 percent more likely than their urban counterparts to report having a disability, with the prevalence of a disability increasing from large metropolitan centers to noncore, rural counties. Moreover, older Americans disproportionately live in rural areas compared to other age groups, therefore making up a larger share of the rural population compared to the share of the urban population. Over 20 percent of Americans over 65 years old live in rural America, compared to only 14 percent of the total American population living in rural areas. Put another way, the share of the older population is higher in rural areas - 17 percent of the rural population is 65 years or older while only 14 percent are over 65 in urban areas (Smith \& Trevelyan, 2019).

All of the challenges mentioned have been especially relevant during the COVID-19 pandemic. A larger share of rural residents than urban lives in counties with high vulnerability to the COVID-19 virus due to underlying health problems, older adult populations, lack of health insurance and distance to a hospital with an intensive care unit (Cromartie et al., 2020). From a healthcare worker perspective, COVID-19 has presented mental health and workload challenges. In October 2020, a survey of 500 nonphysician healthcare workers found that 84 percent were experiencing burnout (Brusie, 2020). In a November 2020 USA Today article, a physician in Poplar Bluff, Missouri discussed how the COVID-19 pandemic exacerbated the shortage of providers in rural areas and increased the workload of already overworked rural providers (Kura, 2020). Furthermore, rural providers are feeling polarized from their communities due to conflicting political views on the validity of the virus and prevention measures. A December 2020 article highlighted the challenges of one rural provider in rural Kansas who left her 
position as the county medical director due to animosity from her community. The article also shared that more than one in four public health administrators in Kansas left their position at some point in 2020 (NPR, 2020). While retaining rural health providers was relevant for rural communities prior to the pandemic, COVID-19 has increased the intensity of the issue.

\section{Rural Healthcare Economic Impact}

The findings regarding the economic impact of rural hospitals are mixed but there is consensus that healthcare does provide a strong employment base in rural counties. According to the U.S. Bureau of Labor Statistics, in 2019 the healthcare and social assistance sector accounted for 10 percent of nonmetro jobs, similar to manufacturing (11 percent) and retail (10.5 percent). Using input-output analysis, Doeksen et al. (1998) found that the health sector accounted for roughly 14 percent of all employment in nine rural Oklahoma counties through both jobs directly in the health sector and secondary jobs resulting from healthcare spillovers. Using national data, Miller, Pender \& Hertz (2017) drew upon export base theory to calculate multipliers through an ordinary least squares (OLS) regression to measure the impact of rural inpatient healthcare facilities like hospitals and nursing homes. They estimated over eight percent of total rural wage and salary jobs were in inpatient healthcare facilities in 2011 , however they found that inpatient healthcare facilities had limited spillover effects on other industries' job creation. Additionally, Miller, Pender \& Hertz (2017) found that employment in inpatient healthcare facilities grew between 2001 and 2015, while manufacturing employment declined. Doeksen et al. (2012) aggregated the findings from the 73 input-output analyses and found that on average, a rural critical access hospital employs 141 employees and creates an additional 0.38 jobs in other businesses for each job within the hospital.

Holmes et al. (2006) studied the impact of hospital closures specifically. Studying all rural counties with hospital closures between 1990 and 2000, they found that the closure of a sole hospital in a rural community reduced per-capita income by four percent and increased the unemployment rate by over one percent. Additionally, between 2007 and 2012, the National Center for Rural Health Works completed 73 economic impact studies of various critical access hospitals covering 21 states. These 
studies used input-output analysis to calculate multipliers effects of critical access hospitals through secondary job creation due to construction needs, development of housing for hospital employees, or other economic activity that benefited from the critical access hospital.

\section{Rural Development through Community Wealth}

Rural-based challenges are not siloed to health care and are easily observed from a demographic and economic standpoint. From a historical perspective, the U.S. was majority rural until the 1950 decennial census, which found that the majority of Americans lived in metropolitan counties. Since then, apart from a few waves of return migration to rural areas, most migration within the United States has been from rural to urban (Johnson and Lichter, 2019). Following the Great Recession of 2007 to 2009 , rural areas struggled to recover as quickly as their urban counterparts. Between 2010 and 2017, real personal income per person grew faster and was significantly higher in metropolitan counties compared to their nonmetropolitan counterparts (Pender et al., 2019). Additionally, nonmetropolitan areas without an urban center greater than 20,000 experienced population loss between 2010 and 2018, and more people out-migrated than in-migrated in rural areas (Pender et al., 2019). Prior to 2010, population change in rural areas had always been positive, however, population growth had been slowing in rural areas for decades (Cromartie \& Vilorio, 2019). These challenges have led researchers and community development practitioners to focus on sustainable strategies for fostering economic growth in rural areas through wealth creation. Pender et al. (2012) defined wealth as the stock of all assets, net of liabilities, that can contribute to the well-being of an individual or group. Therefore, I explore strategies and frameworks that focus on the overall well-being or a community or region, as opposed to only traditional measures of economic growth like income and employment.

In 2004, Flora et al. (2004) published the second edition of Rural Communities: Legacy and Change, which emphasized the importance of various "capitals" rural communities could enhance or draw upon to remain viable and address challenges of the recent decades. Flora et al. (2004) discussed seven capitals important to sustainable economic development - natural, cultural, human, social, political, 
financial, and built capital. Their framework, the Community Capitals framework, became a staple methodology for analyzing and developing rural communities. For example, Emery and Flora's (2009) article that uses the Community Capitals framework to look at community change has 899 citations on Google Scholar.

In 2012, Pender et al. published an USDA ERS Economic Research Report that conceptualized a framework for Rural Wealth Creation. Pender later worked with Fannin, Weber, and Johnson to outline the framework in their book, Rural Wealth Creation (Pender et al., 2014). The book and the report outlined eight forms of capital, differentiated it from Flora et al. (2004) by adding intellectual capital as a separate form of capital from human capital. Pender et al. emphasized promoting wealth as opposed to income as a sustainable way to enhance long-term economic growth; they argue that wealth is a tool for increasing income or consumption and contributing to economic resilience. Furthermore, assessing communities strictly by income or population growth does not capture the complex dynamics or income disparities at play within rural communities. Rural communities are heterogeneous and therefore no onesize fits all development strategy works for every community. The Rural Wealth Creation framework seeks to identify assets and opportunities unique to each community and employ those towards sustainable development.

Due to the complexity of measuring various forms of wealth or capital and the relatively recent creation of the two frameworks, the body of research that applies measures of capital to rural development outcomes is small. However, various authors have developed proxies for each of the eight forms of wealth. For each of the eight forms of capital, I provide historical definitions, previously used indicators or proxies, and briefly discuss the role of each capital in economic development.

\section{Natural Capital}

McGranahan's (1999) natural amenities scale is widely cited as capital measurement.

McGranahan found climate, topography and water area are positively related to rural population and employment change between 1970 and 1996. He found that population growth was correlated with 
attractiveness as a place to live, especially natural attractiveness like mild climate, varied topography, and nearness to water. He developed an index for measuring these attractive natural capitals. The index included six measures - average January temperature, average January days of sun, low winter-summer temperature gap, low average July humidity, topography scale, and water area as a proportion of total county area. McGranahan's scale has become widely used to study the impacts of natural amenities across the rural urban continuum and has garnered over 900 citations in Google Scholar.

More recently, McGranahan and Wojan (2007) studied the rural creative class, modeled after Richard Florida's Rise of the Creative Class (2002), and found natural capital, defined here as mountainous, forested, and warm-wintered areas, is positively associated with the creative class (population of workers in creative professions). ${ }^{1}$ The benefits of attracting creative class workers include increased human capital through education and diverse experiences. Congruent to McGranahan's (1999 or 2007) findings, Chen and Weber (2012) found that communities close to land reserved through the 1994 Northwest Forest Plan experienced higher growth in population in the 1990s. Deller et al. (2001) looked at amenities more broadly and found relationships between amenities and quality of life and local economic performance. Deller et al. (2001) included both climate, topographic, and water variables like McGranahan and urban facilities variables like parks, tourist attractions, fairgrounds, and golf courses. They found similar results to McGranahan (1999) and Chen and Weber (2012) in that various forms of amenities have positive effects on employment and population growth rates. These findings have led to amenities-driven rural development strategies that use natural capital to promote people attraction. Areas endowed with natural amenities are better able to attract educated populations, contributing to the growth of human capital. However, natural amenities-based attraction does not bode well for areas with lesser amounts of natural capital.

${ }^{1}$ Compared to Florida (2002), McGranahan and Wojan (2007) exclude occupations that have limited creative thinking or only engage in economic reproduction. Florida's Creative Class is further described in the upcoming section. 


\section{Social Capital}

Another well-developed association between community prosperity and a form of capital is the importance of social capital to economic development. Robert Putnam's 1993 article, "The Prosperous Community," emphasizes social capital as a way to enhance the benefits of investment in physical and human capital in facilitating economic development (Putnam, 1993). He defines social capital as, "features of social organization, such as networks, norms, and trust that facilitate coordination and cooperation for mutual benefit." In 2000, Putnam published Bowling Alone, a book that outlined his argument for the decline of social capital in the United States. Though his argument that social capital was declining in the United States was widely criticized, the book did outline the important distinction between bridging and bonding social capital. Putnam describes bonding social capital as exclusive or inward looking, while bridging social capital is inclusive or outward looking. Putnam explained that both social capitals are important. Bonding social capital can be perceived as the "glue" that holds groups together, while bridging social capital is the "lubricant" that facilitates relationships between diverse groups.

In 2006, Rupasingha, Goetz \& Freshwater expanded on Putnam's social capital by developing a proxy for social capital at the county level. Rupasingha et al. include ethnic homogeneity, income inequality, attachment to place, education, age and female labor force participation in their social capital index. Deller and Deller (2010) studied how crime rates were affected by social capital-generating institutions. Their proxies for social capital included service-oriented firms like foodbanks, churches, cooperatives, and nonprofits. They found that higher levels of social capital have a dampening effect on rural crime. Conroy and Deller (2020) measured social capital as the concentration of organizations with missions surrounding religion, professional development, civil and social services, health, and labor and found these concentrations to be positively correlated with business survival rates. 


\section{Political Capital}

Political capital provides wealth for communities through the social capital that comes from political and government knowledge and networks. Banfield's book Political Influence described political capital as the stock of influence that politicians gain from their constituents. Pender et al. (2012) further elaborated on this idea and pointed out that political capital could be viewed as a type of social capital because it draws on social networks, reciprocity, and mutual trust. To show the impacts of political capital on economic growth, in 1999 Levitt and Poterba analyzed the impact of Congressional representation on state per capita income growth and found that states with senior congresspersons grew more quickly between 1953 and 1990 than states with more junior congresspersons. Levitt and Poterba recognized, however, that reverse causality prevents drawing any conclusions from these correlations: Does state economic growth increase Congressional power or does Congressional power increase state economic growth? At a smaller geography, Rupasingha and Goetz (2007) find political characteristics of a county to be determinants of poverty. They used per capita federal grants and the absolute value of the difference between the county for the Democratic presidential candidate and the national average for that candidate in national election, arguing that federal grants symbolize an injection of federal funds which should be associated with a reduction in poverty, and county votes closer to the national average should be more politically competitive. While political capital could be viewed as a sub-category of social capital, it may be valuable to assess political capital on its own to capture the impact of assets on wealth creation.

\section{Cultural Capital}

Cultural capital, like social and political capital provides benefit through understanding of societal norms. It can also provide positive economic benefit through cultural diversity. Bourdieu (1986) explained cultural capital using differences in academic achievement between children of different social classes. Bourdieu argued that a child's familial culture, beliefs and traditions played a role in determining academic performance according to how their culture fit in higher social classes. Flora et al. (2004) explain cultural capital as influencing what opinions within a community are valued and how creativity, 
innovation, and influence emerge and are nurtured. Investing in cultural capital through encouraging diversity has been shown to provide economic benefits. Ottaviano and Peri (2006) found that U.S. natives living in metropolitan areas where the share of foreign-born people increased experienced increased wages and higher rental prices for housing. Furthermore, Niebuhr (2009) found that cultural diversity in a region's research and development sector had a positive impact on innovation through increased patent applications. Cultural capital in a rural development setting has yet to be explored in depth, however Pender et al. (2012) suggests race, ethnicity or languages spoken are proxies for cultural capital.

\section{Built Capital}

Built, or physical capital is a tangible example of how wealth can benefit communities. It includes the stock of commercial and residential buildings and infrastructure. Access to highways or interstates is a popular proxy for physical capital in rural places (Van Sandt, et al., 2019; Schmit, et al., 2020). Rephann and Isserman (2002) found that counties benefitted in terms of economic growth when they became connected by interstates and were in close proximity to large cities or had more than 25,000 residents. Broadband networks could be another proxy for physical capital. Due to the growing economic reliance on internet access and focus from policymakers on broadband infrastructure, a body of literature assessing the impacts of broadband internet on rural wealth has developed. Various studies have found a correlation between access to broadband and economic growth through employment growth and firm entry (Kim and Orazem, 2016; Whitacre et al., 2014; Kolko, 2012). Furthermore, Kim and Orazem (2016) found that the effect of broadband has a larger impact on location decision for education and health services compared to manufacturing. At the household level, Deller and Whitacre (2019) found that remote rural housing values are positively impacted by higher broadband access. Moreover, broadband continues to increase in importance for healthcare as telehealth continues to grow. The American Hospital Association reports that telehealth use in hospitals has grown from $35 \%$ of hospitals 
implementing telehealth in 2010 to $76 \%$ of hospitals utilizing telehealth in 2017 (American Hospital Association, 2019). ${ }^{2}$

\section{Human Capital}

Human capital can be described as the human-level assets held by the members within a community. Pender et al. (2012) suggested education, training and health of workers to measure human capital. Arrow et al. (2012) used educational attainment as a basis for computing human capital and found that human capital is a large contributor to increases in per capita wealth. As further evidence of the benefits of educational attainment, Psacharopoulos and Patrinos (2002) compiled a list of point-estimates for returns on investment in education across countries and found that the rate of return for an additional year of schooling in the U.S. ranges from 7.5 to 10 percent. Despite levels of educational attainment increasing in rural areas, rural areas lag their urban counterparts. In regards to college completion, the share of the rural population with at least a bachelor's degree grew from 15 to 19 percent between 2000 and 2015 (Marre, 2017). In urban areas, the share grew from 26 to 33 percent over the same time period (Marre, 2017). These findings show that not only are people in urban areas better educated, the share of the population with higher education is growing faster in urban than in rural areas. What is more, education's relationship with migration patterns adds complexity to the issue. Weber et al. (2007) studied 5,000 families and their migration patterns between 1993 and 1999 and found that educational attainment in 1993 influenced rural families to migrate from nonmetropolitan to metropolitan counties between 1993 and 1999. They also found that higher education decreased the likelihood of poverty for families. These findings show not only is educational attainment key to human capital, but that educational attainment for rural populations is complicated. This idea, often coined as "rural brain drain," has become a focus point for rural researchers (e.g., Carr and Kefalas, 2009).

\footnotetext{
${ }^{2}$ The U.S. Health Resources Services Administration defines telehealth as the "use of electronic information and telecommunications technologies to support and promote long-distance clinical health care, patient and professional health-related education, and public health and health administration."
} 
Return migration aims at combatting the challenges of "rural brain drain" and developing human capital in rural places through drawing on existing social capital. Return migration can be described as the opposite of out-migration. As mentioned before, out-migration from rural places has been occurring since the mid-1900s. However, the 1990s and early 2000s saw an increase in migration from metro counties into nonmetro counties. Like McGranahan (1999) explained, much of this rural in-migration was to rural areas with high natural amenities. Areas without natural amenities have not fared as well. Von Reichert et al. (2013) sought to better understand what motivated in-migration in these counties without a natural amenities advantage. They identified the potential for return migrants, or people who previously lived or were raised in a community, to slow population loss, generate jobs, and increase human, social and financial capital. Additionally, out-migration of young people removes people within the age range to bear children. Return migration may provide an answer for rejuvenating rural populations by increasing the number of young families. They interviewed high school reunion attendees in their late $20 \mathrm{~s}$ and $40 \mathrm{~s}$ and asked "What does your return contribute to the community?" They found that return migrants are often families with children who have gained business skills and diverse life experiences while living away from their home community. The returnees filled high skill positions and became leaders. Many took over family businesses or started new business. The study also found that return migrants were more invested in enhancing their communities through keeping their businesses local and taking over businesses that would have closed due to retirement.

\section{Intellectual Capital}

Until Pender et al. (2012), intellectual capital had been lumped with human capital. Pender et al. (2012) separated intellectual capital from human capital by describing intellectual capital as the manifested products that are developed through human capital. Schmit et al. (2017) provided an example of intellectual capital when they described the value of intellectual capital through the flow of information and education between rural farmers and urban consumers at farmer's markets. To measure intellectual capital, Pender et al. (2012) and Hoffer and Levy (2010) suggest using patents per capita as a proxy for 
intellectual capital due to the tangibility of the metric and access to quality data from the U.S. Patent and Trademark Office. Wojan, Dotzel and Low (2015) assessed rural stocks of intellectual capital and noted that rural areas have low levels of patents per capita. They find, however, that rural inventors have more patents, on average, suggesting intellectual capital in rural areas may be stronger than patents per capita suggest.

\section{Financial Capital}

When considering wealth broadly, most first think of financial capital. Flora and Flora (2004) and Pender et al. (2012) cast aside this notion. They argue that regional and community growth is not siloed to income, nor is it only a factor of access to financial capital. Indeed, the success of regions and attractiveness to potential inhabitants is based in a mix of assets. Flora and Flora (2004) focused on the interaction between capitals to guide community development. They argue that simply having access to financial capital will not result in sustainable growth; growth requires assessing all assets within a place and looking at how they can build upon each other to promote development. Similarly, Pender et al. (2012) advocates for identifying development strategies that are aimed at capitalizing on a multitude of wealth factors identified as strengths of the region to achieve community goals. Like all the other community capitals, financial capital works best in combination with other assets like human capital and social capital to create wealth within communities.

The importance of financial capital to economic development is most easily observed through entrepreneurship — research has found financial capital essential to entrepreneurship and entrepreneurship essential to rural economic prosperity. In regards to my analysis, incorporating financial capital may be important for providers seeking to start their own practices. To promote entrepreneurship, Low (2005) argued that bank deposits are crucial to funding loans for entrepreneurs. Conroy, Low and Weiler (2017) found that small business loans have a positive relationship with job-generating business startups, especially in rural counties. They used small business loan data reported as a requirement of the Community Reinvestment Act. Furthermore, Pender et al. (2012) suggested using household and business 
assets and liabilities for indicators of financial wealth including savings, stocks, bonds, retirement accounts, mortgages and loans.

Having established the financial capital-research link, I move to the importance of entrepreneurship to rural economic development. First wave economic development strategies (post WWII) emphasized recruiting large manufacturing-type business or "smoke-stack chasing" while subsequent second wave economic development strategies focused on retaining and expanding existing businesses (Bradshaw \& Blakely, 1999; Deller 2014) Most contemporaneously, economic development strategies are tied to placemaking, talent attraction and entrepreneurship (Deller 2014). Both Rupasingha and Goetz (2013) and Stephens and Partridge (2011) find positive associations between self-employment rates, a proxy for entrepreneurship, and employment and income growth at the county level in rural areas.

\section{Health Care Provider Retention Literature}

This thesis focuses specifically on provider retention, as opposed to recruitment. While recruitment strategies provide short-term solutions, retention of providers presents a bigger challenge in rural areas and can be costly to rural health care organizations. Only 35 percent of primary care providers remain in the communities they were initially assigned to six years after completing a recruitment program obligation (Negrusa \& Taplin, 2016). Moreover, to draw attention to the fiscal impacts of provider relocation, David Frenz, MD, a vice president of a provider group of over 250 providers, estimated that the cost of provider turnover is at least $\$ 400,000$ per provider (Frenz, 2016). From a community acceptance standpoint, increased provider turnover negatively impacts public and patient perception of their healthcare facilities. This negative perception can lead tobypass behavior, or residents traveling farther than necessary to obtain health care.

Due to these challenges, public health and health care workforce researchers have focused on identifying personal characteristics that promote retention and through providers' integration into their workplaces and the communities they serve. The existing literature indicates three domains impacting long-term provider retention - 1) demographic traits and provider's personal history, 2) characteristics 
and conditions of the provider's workplace, and 3) community characteristics. In this section, I start by discussing the provider-level findings from the literature, followed by workplace characteristics and finish with a breakdown of the impacts of the community capitals on provider retention.

\section{Provider Demographic and Background Characteristics}

The role of a provider's background on their practice location choice has been studied extensively by medical colleges and training programs who track the outcomes of their graduates. However, much of this literature focuses only on where providers chose to practice first, not where they chose to practice long-term. In reviewing the retention-specific literature, four key themes arose as being frequently studied regarding provider retention - familiarity with a rural setting or the community in which they practice, gender, provider type, and resiliency.

\section{Community or Rural Familiarity}

Family ties or having a personal history in a location has been shown to increase provider retention. Pathman et al. (2004) used the American Medical Association's Physician Masterfile to study rural physician location from between 1991 and 1996. They found that physicians serving in rural Health Professional Shortage Areas (HPSAs) were more likely to stay in their community if they were working in a state where they grew up or trained. Additionally, Daniels et al. (2007) compared medical professionals who remained in rural location with those who started their career in a rural area and then relocated. They found that returning to a hometown was a significant predictor of their decision to stay, as well as preference for a certain size of community. Lastly, Hancock et al. (2009) interviewed twenty-two physicians across the rural urban continuum and found familiarity to be a major motivation for practice location. Hancock et al describes familiarity as provider's wanting to live in a natural or social environment that, "gave them a sense of trust, comfort and ease and required less cognitive and social effort than attempting to integrate into a new type of community." This idea of familiarity is not exclusive to locating near family, but instead speaks to the larger idea of choosing to locate in a small town due to being raised in one. Both Daniels et al. (2007) and Hancock et al. (2009) found correlations between 
receiving medical education or participating in a rural training program and the likelihood of providers remaining in a rural location.

\section{$\underline{\text { Gender }}$}

While the effects of gender on rural provider recruitment and retention has been studied frequently, the findings are mixed and do not provide a clear picture of the relationship between gender and rural health care provider retention. The effects of gender have been studied more extensively from a recruitment perspective rather than retention and find that the characteristics most important to each gender differ when selecting a location. Ellsbury et al. (2002) assessed how important factors varied between genders when making location choices in the Pacific Northwest and found that women were more likely to be influenced by family concerns such as flexible scheduling and leave, childcare, and spouse's career. Paladine et al. (2020) found women to be more concerned with forming relationships in the workplace and community when making their location choice. Lindsay (2007) specifically assessed differing motivations for choosing rural practice between male and female mid-level practitioners and found that while men were drawn to autonomy and broad scope of practice in rural areas, women were more concerned about the workplace environment, gaining respect from colleagues and patients, and the challenges of professional isolation.

Literature examining the effect of gender on long-term retention is more sparce and does not suggest strong gender-retention linkages. In regards to long-term retention, Hustedde et al. (2018) conducted qualitative interviews of twenty-five female rural family physicians and found that professional relationships, practice characteristics, and support during times of transition were most important to willingness to remain in a rural setting. When conducting quantitative analysis, gender was controlled for in many studies of retention (Daniels et al., 2007, Pathman et al., 2004; Holmes and Fraher, 2017), but only one found it to be significantly related to provider retention. Stenger et al. (2008) studied primary care physicians in rural Massachusetts and found that female practitioners were more likely to report they 
planned to stay rural throughout the upcoming decade. Stenger et al. went on to specify that their finding may be unique to the New England region, however, due to being close to major urban centers.

\section{Provider Type}

I have data on three types of providers - primary care doctors; dentists; and nurse practitioners, physician assistants, and nurse midwives and I focus only on literature examining retention for the latter group, known as mid-level practitioners. Daniels et al. (2007) found that mid-level practitioners (nurse practitioners, nurse midwifes, and physician assistants) choose a rural practice location throughout their careers significantly more often than other health professional programs including medical doctors. Daniels et al.'s findings are important because one proposed strategy for maintaining health care provision in rural areas is to utilize mid-level provider or advanced practice provider business models. An advanced practice provider, used interchangeably here with mid-level provider, is defined as a health care worker with two or three years of post-secondary training with extensive medical training (Craft, 2017). Examples include nurse practitioners, physician assistants, nurse midwives, and nurse anesthetists. Kushins et al. (2017) provide a good example of the benefits of mid-level provider models by advocating for the use of physician assistants in rural areas. They argue that physician assistant business models can focus on underserved markets and have lower costs while maintaining high quality.

\section{$\underline{\text { Resilience }}$}

Because of the autonomy and isolation that can come with rural practice, the literature identifies resilience as an important characteristic for providers who practice in a rural setting. Hancock et al. (2007) discussed the importance of self-actualization and resilience for provider satisfaction. The authors explain self-actualization as the choice by providers to locate somewhere that was suited for raising children, settling down and making a life for themselves. Additionally, they were satisfied with the variety of work and opportunity to make a difference in rural areas. Resilience was explained as providers' abilities to weather external circumstances and continue to grow by drawing on personal experiences from their past (Hancock et al. (2007). The ideas of self-actualization and resilience are key 
to Cutchin's (1997) findings on integration. Cutchin found that the fourteen physicians he studied were all comfortable with the challenges and diversity that came with rural practice. Furthermore, he notes that physicians who were insecure in their abilities may struggle in the rural setting and those that are prepared to weather stress and fatigue are better able to integrate into the community. Similarly, all of the physicians in Henry and Hooker (2007)'s study described the importance of being confident in their abilities to work autonomously in an isolated setting. When quantitatively analyzing various factors' impacts on long-term retention, it is difficult to find an appropriate proxy for provider resilience, but nonetheless its importance to retention is worth noting.

\section{Workplace Characteristics \& Conditions}

The second domain relevant to provider retention concerns the traits of the workplace and provider's satisfaction with the amount of work and the compensation they receive for it. In describing the importance of integration into a community, Cutchin (1997) argued that the medical community, made up of hospitals, private practices, and the medical personnel within them, play a role in promoting retention. Three themes identified in other literature support this claim - the importance of not feeling overworked, access to other medical colleagues, and financial package.

\section{$\underline{\text { Work-life Balance }}$}

A theme especially relevant to rural providers compared to urban was the workload of the provider. Availability of relief coverage for vacations, holidays and family emergencies was the highest rated factor important to retention in Cutchin et al.'s (1994) survey of 132 primary care physicians in rural Kentucky. Similarly, Stenger et al. (2008) found that not feeling overworked was significantly associated with higher overall satisfaction. Mayo and Matthews (2006) interviewed spouses of rural physicians and found that spouses' contentment was most influenced by the physicians' workload. Furthermore, the literature points out that rural physicians specifically may have less separation between their professional and personal life. Henry and Hooker (2007) noted that despite providers realizing the importance of integrating into their community, they sometimes felt they were always on call due to being located in 
such a tight knit community. Similarly, Hughes (2019) studied general surgeons and found that rural surgeons experienced more personal and professional life overlap than their urban counterparts.

\section{Professional Relationships}

A provider's networks and relationships within the workplace were often identified as being important to provider satisfaction. Both Cutchin et al (1994) and Stenger et al. (2008) highlighted the importance of maintaining professional colleagues and not feeling professionally isolated. Cutchin et al.'s physicians ranked compatibility with others in the medical community, available consultation with a specialist via telephone, and availability of practice partners as important and Stenger et al. found that not being professionally isolated increased practice satisfaction. During qualitative interviews, physician assistants in rural Texas interviewed by Henry and Hooker (2007) described the intellectual isolation and the absence of other colleagues that came with rural practice. Furthermore, while not the focus of this study, the provider location choice literature also points to the importance of professional relationships. Ellsbury et al. (2002)'s study of providers in the Pacific Northwest found that the most important factor to successful recruitment of general practitioners was having good relationships with practice partners.

\section{Financial Package}

The third theme from the existing literature surrounding workplace conditions was the importance of salary or financial package. Conte et al.'s (1992) qualitative study of rural Florida physicians found frustration with lack of income growth potential and Stenger et al. (2008) found similar dissatisfaction with future income. Furthermore, while the financial package is not often one of the first factors considered by providers in the existing literature, much of the literature does note it is a factor. Cutchin et al. (1994) found income potential of greater than $\$ 100,000$ a year to be the seventh most important out of eighteen factors, Daniels et al. (2007) found income potential to be the fourth most important factor out of seventeen factors, and Helland et al. (2010) found salary or signing bonus to be the eighth most common factor out of thirteen. It is important to note that the importance of financial package may be in 
conjunction with work-life balance. Even in instances where rural providers receive equal pay to their urban counterparts, they may work more hours making them desire higher pay.

\section{Community Characteristics}

No existing literature I am aware of specifically assesses the impact of various community capitals on provider retention. Thus, one unique contribution of this analysis is the emphasis on community-level characteristics and how they impact provider retention. However, three of the community capitals arise as important from the existing literature, 1) social capital, 2) human capital, and 3) natural capital. The relationship of social capital to retention is the strongest in terms of breadth of literature. Human capital is discussed due to the importance of K-12 schools to provider satisfaction. Natural capital is discussed in terms of natural amenities or recreational opportunities.

\section{$\underline{\text { Social Capital }}$}

Most of the literature surrounding provider retention and its relationship to the community centered in developing and maintaining social capital - or a provider's networks and relationships within their community. Cameron et al. (2010) specifically explored the community factors that promoted physician retention and found appreciation, connection and active support to be three of the four top characteristics important to provider retention. In the Cameron et al. (2010) study, appreciation took the form of verbal feedback, acknowledgements in the newspaper, and personal cards and gifts. Connection was described as the sense of belonging or integration, and active support manifested through fundraisers for medical facilities, volunteering, befriending physicians' families, and nominating physicians for community awards. Conte et al. (1992) also discussed the importance of community support to physicians' desire to remain in the community. Furthermore, providers' involvement in their communities helped with retention in many studies. Stenger et al. (2008) and Hancock et al. (2009) found a correlation between provider involvement in their home community and retention, and Henry and Hooker (2007)'s physicians all noted the importance of community involvement. Hancock et al. (2009) also discussed the importance of providers' sense of place and desire for familiarity. Furthermore, the impacts of social 
integration were not limited to providers. Mayo and Matthew's (2006) interviews with physician spouses also found community integration to greatly impact spousal contentment. Lastly, while the literature has established the importance of social capital, it also points out the challenges that come with it. Chipp et al. (2011) interviewed providers in Alaska and New Mexico and found that two of the biggest challenges to rural healthcare practice was establishing relationships within the community and having personal and professional boundaries.

\section{$\underline{\text { Human Capital }}$}

Quality of K-12 schools were also important for providers. Cutchin et al. (1994) cited quality of public elementary and secondary schools as important and the physicians in the Conte et al. (1992) study discussed dissatisfaction with the school system. These findings make sense when compared with Pathman et al. (2004), which found that parenting a minor-age child is positively correlated with retention. From a recruitment perspective, quality of schools also mattered when it came to initial location choice. Hughes (2019) found that one of the most important factors for surgeons when choosing their location was the community support for children and K-12 education. Renner et al. (2010) surveyed 93 providers in Colorado and 40 percent of respondents cited "education/school opportunities for children" as important. Similarly, Ellsbury et al. (2002) found that 40 percent of their 114 surveyed physicians felt that a good school system was very important to their location choice.

\section{Natural Capital \& Recreational Activities}

Similar to McGranahan (1999) and Florida (2002), the provider specific literature finds an importance placed on the access to natural capital and recreational activities more broadly defined. Cameron et al. (2010) found that one of the top five themes important to retention of family health care providers was physical and recreational assets of the community. In regards to providers' families, Mayo and Matthews (2006) found that physicians' spouses with access to limited recreational facilities were not as content, but they did value the access to the natural environment that came with a rural setting. From a 
recruitment perspective, Daniels et al. (2007) found that half of the health care providers surveyed felt that cultural and recreational activities were an important factor in choosing their first practice location. 


\section{CHAPTER 3: SURVEY ON RURAL COMMUNITY WEALTH AND HEALTH CARE PROVISION}

The survey data used in this thesis are from the 2015 USDA Economic Research Service (ERS) Survey on Rural Community Wealth and Health Care Provision (SRCWHCP). In 2012, economists and statisticians at USDA ERS and Iowa State University Center for Survey Statistics and Methodology developed a study aimed at improving understanding about (1) how the assets and investments of rural communities affect recruitment and retention of healthcare providers and (2) the effects of rural health care provision on economic development in rural communities. The Survey was born from a desire to better understand how the Rural Wealth Creation framework relates to rural health care provision. To capture regional differences, the research team chose a study area of nine states divided into three regions: Upper Midwest consisting of Wisconsin, Iowa, and Minnesota; Lower Mississippi Delta consisting of Arkansas, Mississippi, and Louisiana; and Southern Great Plains consisting of Texas, Oklahoma, and Kansas. See Figure 1 for a map of the study states. While these three regions all share large rural populations, they vary in regards to health care access, access to urban areas and infrastructure, poverty, and natural amenities.

Figure 1: Map of SRCWHCP regions

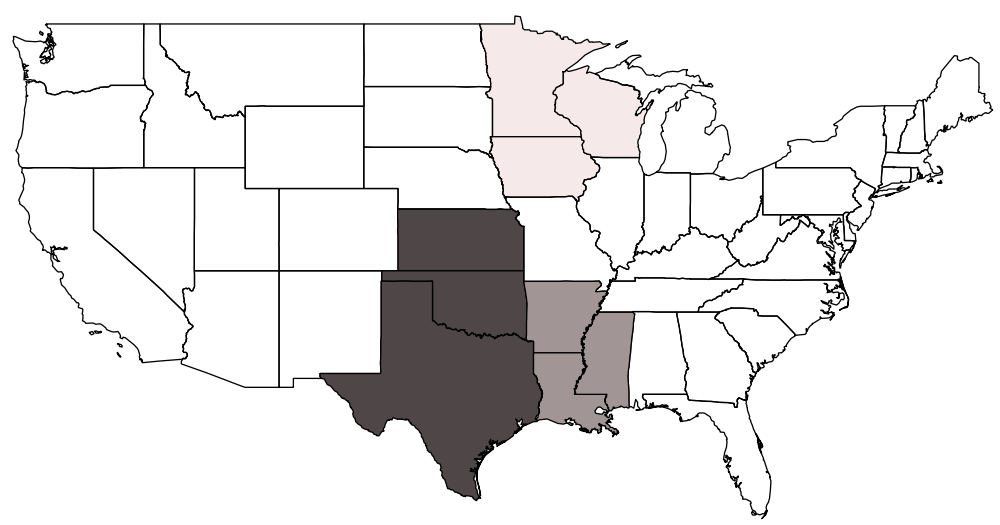

Lower Mississippi Delta (AR, MS, LA)

Southern Great Plains (TX, OK, KS)

Upper Midwest

(IA, MN, WI) 


\section{Sample Selection and Survey Methodology}

Within the nine-state region, zip code tabulation areas (ZCTAs) were used as the primary sampling unit due to the availability of health care access data at this level. ${ }^{3}$ ZCTAs eligible for the survey had populations of between 2,500 and 20,000 in 2008 according to the U.S. Census Bureau. These population limits were chosen because rural communities with fewer than 2,500 were considered unlikely to support a health care provider, and communities larger than 20,000 were considered very likely to have a hospital and would face less challenges in recruiting and retaining health care providers. Typically, ZCTAs have only one incorporated community in rural areas. However, some of the ZCTAs in the study had more than one incorporated community. In these instances, the largest town in the ZCTA was chosen for the sample. To further eliminate areas within economic influence from metropolitan areas, ZCTAs that were part of metropolitan urban core areas and suburban areas with high dependence on commuting to urban areas were not included. Furthermore, exceptionally isolated rural areas not part of a metropolitan or micropolitan core and with low commuting dependence on such areas were eliminated as well. After excluding these ZCTAs, the survey team identified 809 rural small towns. Using stratified random sampling, the survey team randomly selected towns grouped into six strata: the three survey regions and then further divided into communities with a hospital and communities without a hospital. 150 small towns were selected. 131 of the 150 towns had hospitals.

After establishing the survey sample frame, the research team developed a two-part methodology for collecting information related to the two research questions. They developed a close-ended survey to be mailed to providers and conducted phone interviews with two to four "key informants" in the selected towns. ${ }^{4}$ Key informant professions included mayors, economic development organization leaders, and hospital administrators. Using secondary data and information taken from the key informant interviews,

\footnotetext{
${ }^{3}$ The Dartmouth Health Atlas has compiled health care access data at the zip code tabulation area. It was also used to identify which of the sample communities had a hospital which did not.

${ }^{4}$ Via a cooperative agreement with ERS, the Center for Survey Statistics and Methodology at Iowa State University conducted the provider survey and the phone interviews with key informants. The Center was also instrumental in developing the sample, aggregating the data, and calculating survey weights.
} 
the survey team compiled a list of providers within the sample communities. The survey team chose to subdivide providers into three categories: primary care physicians (MDs or DOs); dentists; and an assorted group of physician assistants, nurse practitioners, and nurse midwives. Using stratified simple random sampling, the survey team selected up to 32 providers from each community proportionately across the three provider groups. If there were fewer than 32 providers in the community, all providers received a survey. A final sample of 1,821 providers were mailed the survey.

My analysis draws from the data collected from the mailed provider survey. Both the provider survey and key informant interviews asked questions regarding what was important to recruiting and retaining rural health care providers. The key informant interview portion served to complement the findings of the provider survey while also providing a community stakeholder perspective regarding the role that communities play in rural health care provision. Qualitative analysis and summary statistics of the provider survey and key informant interviews will be included in an USDA ERS report currently under review. In the upcoming data section, I provide more information about the provider survey data collection and response rates and briefly discuss some of the initial findings.

\section{Key Findings from the Key Informant Interviews}

This section provides a brief overview of the findings from the key informant interviews and how they relate to my analysis. I briefly cover these findings because they provide relevant background to how I establish my conceptual and theoretical models. An in depth look at the findings as well as more detail regarding responses by region will be showcased in the forthcoming ERS report.

Both the provider survey and key informant interviews portions of the SRCWHCP asked questions regarding what was important to recruiting and retaining rural health care providers. The ERS report authors summarized responses from the provider survey and thematically coded the responses to the key informant interviews and found that three community capitals were most important to recruitment and retention of rural health care providers - social capital, human 
capital, and physical capital. Natural capital and related amenities were also mentioned but were less important than the first three. These findings provide an optimistic picture for local communities and health care employers since communities and workplaces can realistically invest in improving social, human, and physical capital, unlike natural amenities like recreational lakes, varying topography, and mild temperaments that are outside the control of the community.

Investment in social capital links well with the existing rural provider retention literature that emphasizes the importance of providers integrating into the communities they serve and feeling welcomed and needed by that community (Cutchin, 1997; Stenger et al., 2008, Hancock et al., 2009, Cameron et al., 2010). Examples from the key informants of ways for the community to create social capital include simply being a welcoming community or collaborating with health care employers on recruitment and retention efforts. Human capital was emphasized through frequent mention of the importance of quality schools within the community and a vibrant medical community. Quality schools was mentioned by both the key informants and the providers and parallels the importance of schools discussed in Conte et al. (1992). A vibrant medical community and access to colleagues arose from the provider survey who listed the quality of the medical community, quality of professional colleagues and staff, and opportunities for professional growth as important to their decision to locate in a community. Similarly, physical capital plays a role in a vibrant medical community, although it was less important to both the providers and the key informants. Providers felt that the quality of the medical facilities, and furthermore, the investment in continual improvement in medical facilities and equipment were important to recruitment and retention. Key informants took a different approach to physical capital by emphasizing the lack of appropriate housing for professionals migrating to the community. 


\section{Data for this Thesis}

The provider survey portion provided a rich dataset with a high number of observations for econometric analysis. The SRCWHCP provider survey contained 53 questions, 45 of which were closedended. Of the 45 closed-ended questions, fifteen questions asked about personal history and provider demographics, nine questions asked about the provider's work environment or responsibilities, nine asked about recruitment and retention, six asked about the availability and quality of healthcare in the community, and six asked about the provider's volunteering and leadership activities. A complete list of the survey questions can be found in Appendix A.

After secondary data analysis and speaking with the key informants, the survey team found that 131 of the 150 sample towns had providers. The survey questionnaire was then mailed to the 131 study towns that had providers in the three chosen categories - primary care physicians; mid-level practitioners as defined as nurse practitioners (NP), physician assistants (PA), and certified nurse midwives (MW); and dentists. The survey was conducted in three phases: a pilot phase, a first full phase, and a final nonresponse follow up phase over the course of 2014 and 2015. For the pilot phase and first full phase response rates were low with only 23 percent responding. For the final nonresponse follow up phase, all of the providers who responded to the survey, including providers who responded in the first full phase, were mailed an appreciation letter and a $\$ 40$ gift. Due to the incentivization, the final response rate grew to 64 percent. The survey team conducted statistical tests between the results of the three phases and found little evidence of non-response bias between initial respondents and respondents who responded in later phases. After all phases, a total of 927 providers responded to the survey. Tables 1 and 2 provide a complete look at the response rates according to the survey sample. Table 3 provides a matrix of number of responses by both region and provider type.

Table 1: Survey response outcomes by region (after incentives)

\begin{tabular}{|l|c|c|c|c|}
\hline Number in & UMW & SGP & LMD & Total \\
\hline Sample & 951 & 513 & 357 & 1821 \\
\hline
\end{tabular}




\begin{tabular}{|l|c|c|c|c|}
\hline Not Eligible & 132 & 141 & 97 & 370 \\
\hline Eligible Sample & 819 & 372 & 260 & 1451 \\
\hline Refuse & 14 & 19 & 2 & 35 \\
\hline No Response & 242 & 125 & 128 & 495 \\
\hline $\begin{array}{l}\text { Completed } \\
\text { Surveys }\end{array}$ & 563 & 228 & 130 & 921 \\
\hline Response Rate & $68.7 \%$ & $61.3 \%$ & $50.0 \%$ & $63.5 \%$ \\
\hline
\end{tabular}

Table 2: Survey response outcomes by provider type (after incentives)

\begin{tabular}{|l|c|c|c|c|}
\hline Number in & Dentists & NPs/PAs/MWs & Physicians & Total \\
\hline Sample & 472 & 562 & 787 & 1821 \\
\hline Not Eligible & 78 & 145 & 147 & 370 \\
\hline Eligible Sample & 394 & 417 & 640 & 1451 \\
\hline Refuse & 10 & 11 & 14 & 35 \\
\hline No Response & 110 & 131 & 254 & 495 \\
\hline $\begin{array}{l}\text { Completed } \\
\text { Surveys }\end{array}$ & 274 & 275 & 372 & 921 \\
\hline Response Rates & $69.5 \%$ & $65.9 \%$ & $58.1 \%$ & $63.5 \%$ \\
\hline
\end{tabular}

Table 3: Survey Responses by Provider Type and Region

\begin{tabular}{|l|l|l|l|l|}
\hline & Physician & NP/PA/MW & Dentist & Total \\
\hline Mississippi Delta & 53 & 43 & 34 & 130 \\
\hline $\begin{array}{l}\text { Southern Great } \\
\text { Plains }\end{array}$ & 98 & 67 & 66 & 231 \\
\hline Upper Midwest & 224 & 165 & 177 & 566 \\
\hline Total & 375 & 275 & 277 & 927 \\
\hline
\end{tabular}


All regions and provider types generated over a 50 percent response rate. The most responsive region was the Upper Midwest with 69 percent of all providers responding. The most response provider type was dentists with 69 percent responding as well. Conversely, the lowest regional response rate was the Lower Mississippi Delta was a 50 percent response rate. The provider type with the lowest response rate was physicians with 58 percent.

Most providers who responded to the survey were white ( 92 percent), married ( 88 percent), and had graduated high school in the state where they now worked (70 percent). There were only slightly more male respondents ( 509 or 55 percent) than female (418 respondents or 45 percent). Of the 927 respondents, 911 provided their ages. Those ages ranged from 25 to 94 with a median of 48 years old. Regarding family characteristics, roughly half the respondents had no children at home or no children under the age of 18 in the household (452 respondents or 49 percent). Between one and three children were present in the home of 44 percent of respondents and more than four children were in the home of eight percent of respondents. Additionally, providers were familiar with rural areas. The majority of the respondents said that they had grown up outside of town or in a community with less than 20,000 people (67 percent) and had completed an internship, externship or residency in a rural area (60 percent).

Furthermore, many of the providers had long term ties to the community in which they worked. Almost 30 percent of respondents stated they had previously lived in the community prior to working there (272 respondents). Similarly, length of time in the community ranged from less than a year to 57 years, with 13 years being the median and the median year of arrival being 2002. Regarding race and ethnicity, respondents were primarily non-Hispanic whites with 92 percent identifying as white and 96 percent identifying as non-Hispanic. Being an international medical graduate was rare with only 23 respondents having attended high school outside the United States, making up only 2.5 percent of the respondents. Table 4 provides a summary of the key demographic and familial characteristics outlined in this section. 
Table 4: Survey respondent demographic and familial characteristics

\begin{tabular}{|l|l|}
\hline$\%$ white & $92 \%$ \\
\hline$\%$ married & $88 \%$ \\
\hline$\%$ male & $55 \%$ \\
\hline$\%$ female & $45 \%$ \\
\hline Median age & 48 years \\
\hline No children at home & $49 \%$ \\
\hline$\%$ with 1 to 3 children under 18 in household & $44 \%$ \\
\hline$\%$ with four or more children in household & $8 \%$ \\
\hline $\begin{array}{l}\% \text { that grew up outside or town or a community of less than } \\
20,000\end{array}$ & $67 \%$ \\
\hline $\begin{array}{l}\% \text { that completed an internship, externship, or residency in } \\
\text { a rural area }\end{array}$ & $60 \%$ \\
\hline $\begin{array}{l}\% \text { that had previously lived in the community prior to } \\
\text { working there }\end{array}$ & $30 \%$ \\
\hline Median number of years in the community & 13 years \\
\hline$\%$ non-Hispanic & $96 \%$ \\
\hline$\%$ International medical graduates & $2.5 \%$ \\
\hline
\end{tabular}




\section{CHAPTER 4: CONCEPTUAL FRAMEWORK}

The comprehensiveness of the provider survey questions, high response rates, and large sample of the SRCWHCP provides a unique research opportunity to assess the hypotheses that arise from previous rural health care provider retention studies but lacked large sample sizes. The hypotheses below were created based on the initial findings of the ERS Economic Information Bulletin manuscript and findings from previous literature.

Malcom Cutchin's 1997 paper that advocates for provider integration into a place by establishing connections to one's inner self, the workplace, and the community may be the most obvious proponent of the importance of providers establishing social capital within a community. To reinforce Cutchin's belief in the importance of establishing social capital, Conte et al. (1992), Stenger et al. (2008), Hancock et al. (2009), and Cameron et al. (2010) all find associations between community involvement and establishing personal connections as important to retention. Similarly, the qualitative and quantitative analysis of the provider survey and key informant interviews repeatedly showcased the role that communities can take in welcoming and supporting health care providers (i.e., building social capital). Because of these findings, my first hypothesis concerns the role of social capital in provider retention.

Hypothesis 1: Establishing social capital within the community they work negatively impacts providers' likelihood of considering relocating.

Prior literature suggests workplace characteristics and professional opportunities are important for provider retention. Conte et al. (1992) discusses the importance of access to growth opportunities and the potential for growth in earnings, Cutchin et al. (1994) cites availability of relief coverage and consultation services and compatibility with others in the medical community, and Stenger et al. (2008) finds not feeling overworked and professionally isolated as important. Due to the availability of survey data related to these workplace components, my second hypothesis reflects the role of workplace in provider retention. 
Hypothesis 2: Workplace characteristics and satisfaction with work-life balance impact providers' likelihood of considering relocating.

High levels of self-employment in a community have been linked to overall employment and income growth in a community (Bradshaw \& Blakely, 1999; Partridge, 2011). Because my thesis focuses on how rural health care provider retention is not only aided by rural community assets, but also can aid Rural Wealth Creation and rural health care provision, I have included a unique hypothesis regarding retention and entrepreneurship not previously seen in the provider retention literature. I hypothesize that providers who invest in multiple forms of capital to start their own practices or clinics have an incentive to remain in the community to capitalize on their initial investments.

Hypothesis 3: Providers who invest in starting their own practices and engage in entrepreneurship are less likely to consider relocating. 


\section{CHAPTER 5: EMPIRICAL MODEL}

My empirical model uses a combination of the information collected from the provider survey, provider sentiment regarding the importance of various factors to remaining in the community, and secondary measures of community wealth to predict the probability of a provider's willingness to leave his or her community.

To provide a high-level overview of my empirical model: I run a multi-variate regression using a binary dependent variable. I draw my predicted value from the provider survey question that asks "Have you ever seriously considered moving and practicing in a different location?" and regress it on three vectors - a vector containing provider historical and demographic characteristics, a vector containing a list of factors providers ranked as important or not important to their decision to continue practicing in the community, and a vector of county level characteristics that provide proxies for measures of various types of wealth. Due to the lengthy list of variables within each vector, I employ the Wald test to identify which variables are jointly insignificant to the model. Because of endogeneity issues arising from using multiple survey questions that may be related to an unobserved factor, I run a third model using heteroscedasticity to identify and estimate the effects of endogenous regressors conceptualized by Lewbel (2012).

\section{Dependent Variable}

Question 25 of the provider survey portion of the SRCWHCP asks, "Have you ever seriously considered moving and practicing in a different location?" The providers responded with either "Yes" or "No." Of the 927responses to the survey, 398 providers or 43 percent responded "yes," they had considered moving and practicing in a different location. Using the responses from Question 25, I generated a binary variable indicating whether or not a respondent had considered moving with "1" being those that had consider moving and " 0 " as those who had not considered moving. Based on the established hypotheses, Question 25 was selected as the best option for the outcome variable. 
Using the binary variable created from Question 25 as the dependent variable means my model must be a binary response model. I have chosen to use a probit model regression. By using a probit model, I am able to estimate the impact that each test variable has on the likelihood or probability that the provider has considered leaving the community. It is important to note that Question 25 asks, "Have you considered moving?" The survey did not collect responses from health care providers who had acted on the consideration and moved from their community.

\section{Explanatory Variables}

\section{Provider Personal and Workplace Characteristics}

The SRCWHCP provider survey captured a wide range of provider demographic and workplace characteristic data that allow me to assess the impact of a provider's individual background and personal life characteristics on whether he or she had considered moving. A complete list of the individual and workplace characteristic variables included in the analysis can be found in Table 5.

Table 5: Provider personal and workplace characteristic variables taken from the survey

\begin{tabular}{|l|l|l|l|l|l|}
\hline Variable name & N & Mean & Std. Dev. & Min & Max \\
\hline Np/pa/mw & 927 & 0.30 & 0.46 & 0 & 1 \\
\hline Physician & 927 & 0.40 & 0.49 & 0 & 1 \\
\hline Owner & 924 & 0.37 & 0.48 & 0 & 1 \\
\hline Female & 927 & 0.45 & 0.50 & 0 & 1 \\
\hline Log_age & 911 & 3.86 & 0.26 & 3.22 & 4.54 \\
\hline Log_hoursworked & 915 & 3.72 & 0.33 & 1.61 & 4.79 \\
\hline Kids & 927 & 1.18 & 1.35 & 0 & 4 \\
\hline Married & 910 & 0.89 & 0.31 & 0 & 1 \\
\hline Underrepresented_minority & 927 & 0.09 & 0.28 & 0 & 1 \\
\hline Ruraltrain & 904 & 0.59 & 0.49 & 0 & 1 \\
\hline Prural & 912 & 2.24 & 0.96 & 0 & 1 \\
\hline Livedbefore & 924 & 0.29 & 0.46 & 0 & 1 \\
\hline Commute & 914 & 2.83 & 1.59 & 1 & 5 \\
\hline Oncall & 921 & 0.05 & 0.22 & 0 & 1 \\
\hline Coverage & 919 & 0.86 & 0.35 & 0 & 1 \\
\hline Volunteer & 921 & 0.84 & 0.37 & 0 & 1 \\
\hline Leadership & 921 & 0.19 & 0.39 & 0 & 1 \\
\hline
\end{tabular}




\section{Provider Type}

I control for provider type by including both the $N P / P A / M W$ providers and Physician providers, making Dentists the omitted condition for provider type. I hypothesize that entrepreneurship and investing financial capital in one's own practice incentivizes providers to remain in their community. To test this hypothesis, I use data from Question 13 of the survey which asked providers whether they were a sole owner, part-owner, or employee of their practice. I have created a binary variable, owner, that reflects whether the provider is either a sole or part owner of their practice.

\section{Demographics and Familial Characteristics}

I control for provider demographics. Prior studies have found gender is associated with willingness to practice in a rural area (Daniels et al., 2007; Pathman et al., 2004), and Stenger et al. (2008). Like these studies, I have included a binary variable for whether or not the provider was female to capture gender effects. I control for provider race and ethnicity by including the binary variable underrepresented_minority to capture any providers who identified as a race other than White or identified as Hispanic. Lastly, Question 47 asked the provider's age. Providers at different stages of life may be more or less likely to stay in the community they practice in, so I include a variable for age. Because the effect of age may be nonlinear, with younger providers more likely to move, I include the natural log of the provider's age, log_age.

Household structure, e.g., children and marital status, also likely affects mobility. Pathman et al. (2004) found parenting a minor-age child to be an indicator of providers remaining in a community, and both Cutchin et al. (1994) and Conte et al. (1992) discuss the importance of access to good school systems for providers' children as important to retention. Question 51 of the survey asked for the provider's household size, broken down by members over eighteen and members under eighteen. To capture the number of dependents in the provider's home, I used the data from Question 51 to create a variable, kids, that specifies the number of children in the household. The number of children varied from 0 to 12 . To account for this heterogeneity, and because I suspected that having Y children did not make 
school quality twice as important as Y/2 children, I cut-off kids at four children. The provider's marital status may also affect a household's desire to move. Options were married or living as married, divorced or separated, widowed, or single never married. I created a binary variable using Question 50, married, that equals 1 if the provider answered as married or living as married, and 0 for all other responses.

\section{Rural History}

Daniels et al. (2007) and Hancock et al. (2009) highlight the importance of rural training and a provider's history in rural areas as being important to a provider's decision to practice in a rural area. For my study, I seek to understand how rural training and a provider's history in rural areas impacts their willingness to leave after choosing to practice in a rural place. Question 7 from the survey asks if the provider spent any part of their residency, an internship, or externship in a rural area or small town of less than 20,000 people. Using this yes or no question, I have created a binary variable, ruraltrain, for whether or not the provider had received any rural training prior to practicing. Additionally, Question 9 asked providers where they grew up with categories ranging from at least three miles outside of a town to a city or metropolitan area. Using the data, I created a binary variable, providerrurality, for whether or not the provider had grown up in a town of less than 20,000 people or smaller. Pathman et al. (2004) found that working in the state where one grew up or trained had an impact on retention and Daniels et al. (2007) found that providers who returned to their hometown were more likely to remain, so I include a binary variable, fromstate, for whether or not a provider graduated high school in the state where they now work.

\section{$\underline{\text { Workplace Conditions }}$}

The provider survey also collected information on a provider's workplace characteristics and conditions. Multiple components of working conditions have been described as important in the literature. Stenger et al. (2008) cited the importance of not feeling overworked, Conte et al. (1992) noted the importance of having opportunities for professional growth, and Cutchin et al. (1994) cited availability of relief coverage and consultation services and compatibility with others in the medical community important. Using these prior indicators of retention, I use three variables in my regressions to capture the 
effects of workplace satisfaction on likelihood to consider leaving. In Questions 14 and 15, providers responded with the number of hours they worked per week in their place of work community and in other communities. Answers ranged from less than 10 to over 80 hours a week. To minimize the potential for skewed effects due to the large range of hours, I use the natural log of providers' weekly hours, log_hoursworked. Additionally, two questions asked about providers' workload conditions. Question 16 asked providers to choose whether their on-call responsibilities were either acceptable or unacceptable, and Question 17 asked if providers had adequate professional coverage while on vacation. I include two variables created from these questions - oncall, a binary variable of 1 if a provider feels they have unacceptable on-call responsibilities and 0 if they do not feel they have unacceptable on-call responsibilities; and coverage, a binary variable of 1 if the provider felt they had adequate coverage when on vacation and 0 if they did not feel they had adequate coverage.

\section{$\underline{\text { Social Capital }}$}

Lastly, as mentioned in the literature review, social capital and integration into the communities where providers work is important to provider retention. Cameron et al. (2010) lists connection with the community as one of four key factors as important to retention, and Stenger et al (2008) and Hancock et al. (2009) cite community involvement as key to retention. Questions 38 through 41 asked providers to state their level of involvement in volunteer activities and whether they hold leadership positions in local government or civic organizations in the community they work. Using these data, I have created a binary variable, volunteer, that is 1 if a provider responded they had some or a lot of involvement in a volunteer activity. Furthermore, I include leadership, a binary variable for whether or not the respondent holds a leadership position within the community.

Lastly, Question 11 asked where providers lived in relationship to the community with categories ranging from within the city limits to 20 miles or more from town. Using responses to Question 11, I include a categorical variable, commute, of 1 through 5 to reflect the provider's home's proximity to the 
place where they work. If the provider lives far away from where they work, they likely have less connection and social capital with the community.

\section{Important Factors for Retention}

Question 24 of the SRCWHCP provider survey asks, "How important to you are each of the following reasons for continuing to work in this community?" Respondents were asked to respond to each of 22 questions with a Likert scale of not important, somewhat unimportant, neutral, somewhat important, and very important. The 22 factors rate to family-life, the community they lived in, and their place of employment. A full list of the factors can be seen in Table 6. The factors can be divided into three groups: factors that are reflective of the provider's familial situation, factors that reflect the provider's satisfaction with his or her work and workplace, and factors that correlate with various community capitals. Figure 2 provides an illustration of the top ten factors most commonly cited as "important" or "very important.," with regional breakdowns. The factor most often cited as important was "friendliness of the people, good friendships" with over 82 percent or respondents citing it as important, followed by "need for service, having an impact" with 75 percent, and "reasonable workload" with 71 percent. Factors ranked most often as unimportant included "cultural amenities," "low taxes," and "spouse or partner has a good job or career." 
Table 6: How important to you are each of the following reasons for continuing to work in this community? $1=$ not important, $2=$ somewhat not important, $3=$ neutral, $4=$ somewhat important, $5=$ very important

\begin{tabular}{|l|l|l|l|l|l|}
\hline Variable & $\mathbf{N}$ & Mean & Std. Dev. & Min & Max \\
\hline $\begin{array}{l}\text { Your family is settled there; don't want to uproot } \\
\text { them }\end{array}$ & 911 & 3.82 & 1.39 & 1 & 5 \\
\hline Your spouse or partner has a good job/career & 908 & 2.91 & 1.57 & 1 & 5 \\
\hline Relatives or friends are nearby & 915 & 3.61 & 1.38 & 1 & 5 \\
\hline Good place to raise a family & 914 & 3.80 & 1.35 & 1 & 5 \\
\hline Quality of schools & 916 & 3.53 & 1.34 & 1 & 5 \\
\hline Size of town & 916 & 3.43 & 1.18 & 1 & 5 \\
\hline Recreational opportunities & 915 & 3.24 & 1.23 & 1 & 5 \\
\hline $\begin{array}{l}\text { Natural amenities (climate, scenery, } \\
\text { lakes/rivers/oceans, etc.) }\end{array}$ & 920 & 3.33 & 1.25 & 1 & 5 \\
\hline $\begin{array}{l}\text { Cultural amenities (local arts, historical sites, cultural } \\
\text { events, etc.) }\end{array}$ & 914 & 2.70 & 1.13 & 1 & 5 \\
\hline Your involvement in community activities & 916 & 3.29 & 1.21 & 1 & 5 \\
\hline Friendliness of the people, good friendships & 920 & 4.08 & 0.96 & 1 & 5 \\
\hline Availability of goods and services & 917 & 3.09 & 1.07 & 1 & 5 \\
\hline Low taxes & 917 & 2.74 & 1.15 & 1 & 5 \\
\hline Low cost of living & 913 & 3.01 & 1.15 & 1 & 5 \\
\hline $\begin{array}{l}\text { The need for health care providers in the community, } \\
\text { having a positive impact through your practice }\end{array}$ & 918 & 4.00 & 0.99 & 1 & 5 \\
\hline
\end{tabular}


Figure 2: Factors cited as "important" or "very important" by providers in their decision to continue working in the study town

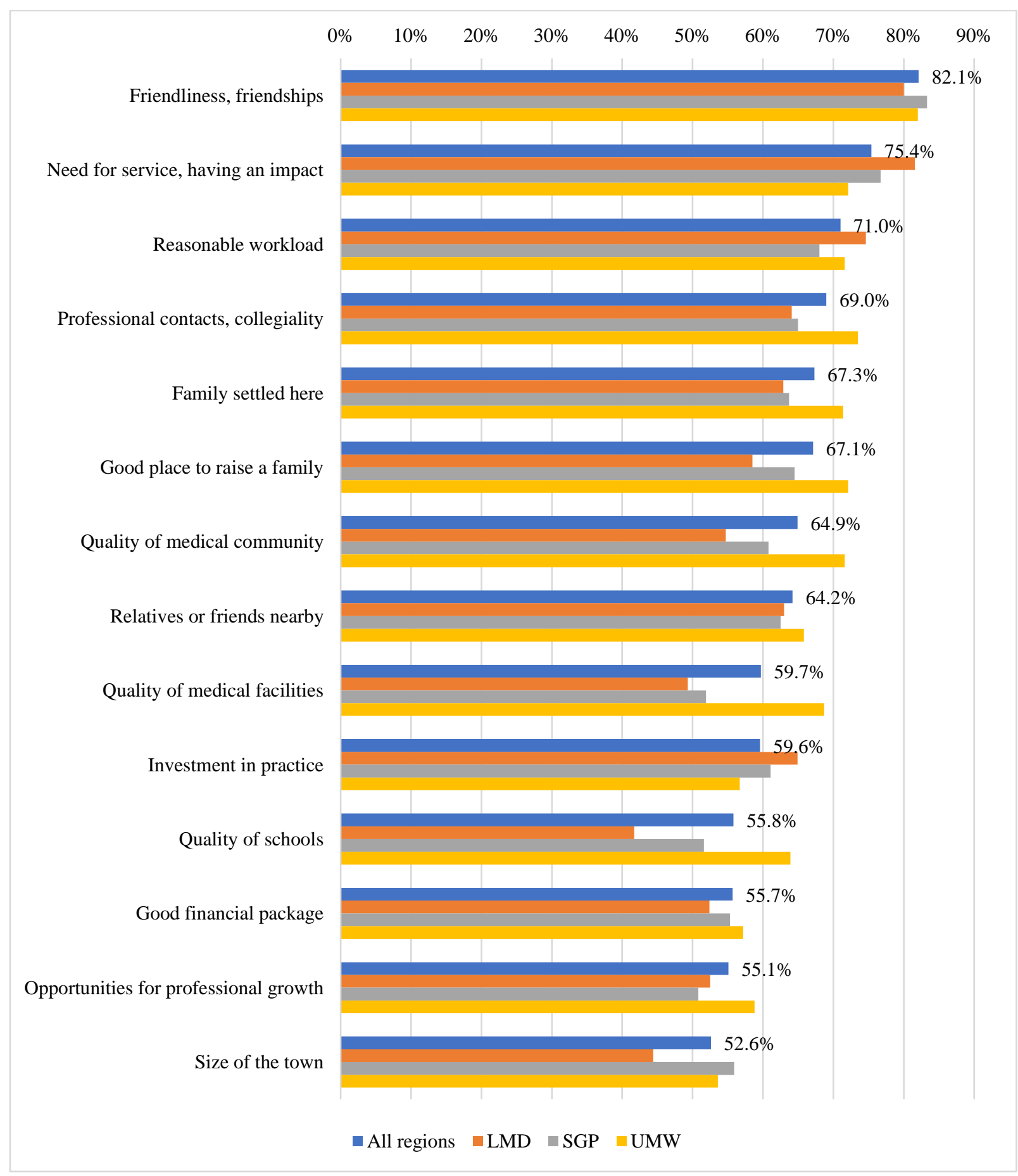

Source: USDA, Economic Research Service analysis of the Survey of Rural Community Wealth and Health Care Provision 
It is important to note that both the dependent variable of whether the respondent had considered moving and the responses to the factors listed in Question 24 were both collected from the same survey. The respondent was asked to state whether they had considered leaving their job or community at the same time as being asked what was important for their decision to stay. Due some of the factors included in Question 24 potentially being related to an unobserved factor outside the survey, including the Question 24 factors creates an endogeneity concern. Instrumental variables may provide a solution to the endogeneity issue. This issue will be addressed in the model section.

\section{County-level Control Variables}

I have included five variables at the county level and one variable at the town level to reflect characteristics relating to rurality, income, and characteristics that impact health care or reflect the availability of healthcare. Because the providers selected for the survey were chosen based on the towns they worked in, I have included the 2010 population of the town as reported by the U.S. Census Bureau's American Communities Survey for the 131 towns in the sample. To provide more insight on population demographics, I include the share of the population in between 2009 and 2013 that was 65 years or older, also taken from the American Communities Survey. This age range is especially relevant to my analysis because people over 65 are more likely to have greater healthcare needs. Similarly, to address healthcare challenges within the county, I include the share of the county population without health insurance from the 2009 through 2013 American Community Surveys. To include measures of healthcare access, I include whether or not any part of the county was designated as a Healthcare Provider Shortage Area (HPSA) in 2010 and the number of primary care physicians per 100,000 people in the county in 2013, both taken from the Health Resources and Services Administrations Area Healthcare Resource Files. Lastly, I use the per capita income of the county for 2013 taken from the U.S. Bureau of Economic Analysis Local Area Personal Income accounts to capture any income-related effects. Table 7 provides a summary of my county control variables. 
Table 7: County-level control variables

\begin{tabular}{|l|l|l|l|l|l|l|}
\hline Variable name & Source & N & Mean & Std. Dev. & Min & Max \\
\hline Acspop10 & $\begin{array}{l}\text { U.S. Census Bureau } \\
\text { American Communities } \\
\text { Survey, 2010 }\end{array}$ & 927 & 6632.40 & 3615.67 & 532.00 & 16361.00 \\
\hline Hpsa10 & $\begin{array}{l}\text { HRSA Area Health } \\
\text { Resource Files }\end{array}$ & 927 & 0.52 & 0.50 & 0.00 & 1.00 \\
\hline Perpop65plus13 & $\begin{array}{l}\text { U.S. Census Bureau } \\
\text { American Communities } \\
\text { Surveys, 2009 - 2013 }\end{array}$ & 927 & 16.76 & 3.21 & 9.70 & 32.50 \\
\hline Phys_uninsured13 & $\begin{array}{l}\text { U.S. Census Bureau } \\
\text { American Communities } \\
\text { Surveys, 2009 - 2013 }\end{array}$ & 927 & 12.48 & 5.76 & 5.40 & 38.80 \\
\hline Pci_13 & $\begin{array}{l}\text { HRSA Area Health } \\
\text { Resource Files }\end{array}$ & 927 & 59.38 & 26.14 & 10.95 & 181.18 \\
\hline $\begin{array}{l}\text { U.S. Bureau of } \\
\text { Economic Analysis } \\
\text { Local Area Personal } \\
\text { Income accounts }\end{array}$ & 927 & 39799.99 & 6424.69 & 27685.00 & 55799.00 \\
\hline
\end{tabular}

\section{Rural Wealth Creation Variables}

My hypotheses seek to understand the role of social capital and entrepreneurship specifically in promoting provider retention in rural areas. Because of social capital and entrepreneurship's ties to many of the other community capitals, I include a proxy for each of the eight community capitals laid out by Pender et al. (2014). While the important factors from Question 24 mentioned above assess the providers' perceptions of what community capitals may be important to retention, I also include a subjective, secondary representation of these capitals through county-level secondary data. Using the existing community capital and Rural Wealth Creation literature (Pender et al., 2012), I have included a proxy for each of the eight capitals in the analysis. These proxies are included in the regression at the county level, instead of town level, due to data availability constraints. I also argue that the larger context (county) is more relevant for wealth creation than values only for the town as many providers and patients do not live in the small town. The summary statistics for the Rural Wealth Creation variables can be found in Table 8. 
Table 8: Rural Wealth Creation variables

\begin{tabular}{|l|l|l|l|l|l|l|l|}
\hline $\begin{array}{l}\text { Variable } \\
\text { name }\end{array}$ & $\begin{array}{l}\text { Community } \\
\text { Capital }\end{array}$ & Source & N & Mean & $\begin{array}{l}\text { Std. } \\
\text { Dev. }\end{array}$ & Min & Max \\
\hline $\begin{array}{l}\text { Social } \\
\text { capital, 2009 }\end{array}$ & $\begin{array}{l}\text { Social \& } \\
\text { Political }\end{array}$ & $\begin{array}{l}\text { Rupasingha, } \\
\text { Goetz and } \\
\text { Freshwater (2006) }\end{array}$ & 927 & 0.53 & 1.11 & -1.70 & 4.50 \\
\hline $\begin{array}{l}\text { Perotherlang } \\
\text { uage13 }\end{array}$ & Cultural & $\begin{array}{l}\text { Census Bureau } \\
\text { American } \\
\text { Communities } \\
\text { Survey, 2013 }\end{array}$ & 927 & 6.86 & 7.88 & 0.50 & 65.90 \\
\hline $\begin{array}{l}\text { Bachelorsplu } \\
\text { s13 }\end{array}$ & Human & $\begin{array}{l}\text { Census Bureau } \\
\text { American } \\
\text { Communities } \\
\text { Survey, 2013 }\end{array}$ & 927 & 19.23 & 5.92 & 7.10 & 43.60 \\
\hline $\begin{array}{l}\text { Eduexppp1_1 } \\
3\end{array}$ & Human & $\begin{array}{l}\text { National Center } \\
\text { for Education } \\
\text { Statistics } \\
\text { Common Core of } \\
\text { Data }\end{array}$ & 927 & 11409.97 & 2100.33 & 7424.06 & 24374.27 \\
\hline Patentspc13 & Intellectual & $\begin{array}{l}\text { U.S. Patent \& } \\
\text { Trademark Office }\end{array}$ & 912 & 0.00 & 0.00 & 0.00 & 0.00 \\
\hline Depositspc13 & Financial & $\begin{array}{l}\text { Federal Deposit } \\
\text { Insurance } \\
\text { Corporation }\end{array}$ & 927 & 15.81 & 6.47 & 3.76 & 39.65 \\
\hline Perwaterarea & Natural & $\begin{array}{l}\text { USDA Amenities } \\
\text { Scale }\end{array}$ & 927 & 3.41 & 6.36 & 0.02 & 68.41 \\
\hline HwyExit & Built & Low et al. (2020) & 927 & 0.43 & 0.50 & 0.00 & 1.00 \\
\hline Bbhsrate201 & $\begin{array}{l}\text { Federal } \\
\text { Communications } \\
\text { Commission, } \\
\text { 2012 }\end{array}$ & 927 & 3.07 & 0.70 & 2.00 & 5.00 \\
\hline
\end{tabular}

Rupasingha, Goetz, and Freshwater (2006) developed a measure of social capital by aggregating the number of organizations and establishments that facilitate the bonding and bridging of social capital at the county level and using principal component analysis to create an index. Besides including the numbers of organizations and establishments where people socialize and connect with others, Rupasingha, Goetz, and Freshwater's measure of social capital includes both the voter turnout for the 2008 Presidential Election and the 2010 Bicentennial Census response rate. Pender et al. (2012) suggests voter turnout and Census response rates as appropriate proxies for political capital. Because these two 
measures are included in Rupasingha, Goetz, and Freshwater's social capital index, I use the social capital index as a proxy for both social capital and political capital.

As mentioned by Arrow et al. (2012), one of the most widely used proxies for human capital is the level of education of the population. I include the share of the population with a bachelor's degree or higher for each county in 2013, taken from the American Communities Survey. Additionally, due to the emphasis placed on schools by both the key informants and the health care providers in the initial summary analysis of the survey for the ERS Economic Information Bulletin, I include the school district expenditures per student, taken from the National Center for Educational Statistics Common Core of Data, aggregated to the county level.

In regards to natural capital, Deller (2001), McGranahan and Wojan (2007), and Weber and Chen (2012) all found measures of growth to be related to natural amenities such as bodies of water, mild temperatures, forest lands, and topography. When comparing the natural amenities of the regions included in this survey, access to bodies of water differs across the three regions. The Upper Midwest, specifically Minnesota, is rich with recreational lakes while the Southern Great Plains has much less access to fresh water. From an ocean access perspective, two of the three states in the Lower Mississippi Delta border the ocean, but Arkansas is less known for its natural amenities. Because of the variation across the regions, I include the share of the county in water area in my regression as a proxy for natural capital, taken from McGranahan's (1999) natural amenities scale.

The importance of built capital to economic development have been established through roadway infrastructure and broadband access (Kim and Orazem, 2016; Whitacre et al., 2014; Kolko, 2012; Rehann and Isserman, 2002). Thus, I include built capital through two proxies - whether or not the county has a major interstate exit and the broadband adoption rate in the county in 2012. The interstate exit variables was calculated in ArcGIS using TIGER line files and is explained in, and obtained from, Low et al., 2020. Highway exits is especially relevant due to the frequent mentions of the challenges of rurality in the survey and key informant interview analysis for the ERS report. Both providers and key informants felt 
that one of the biggest detriments of their communities was the "rurality," explained as being far from major metropolitan areas and not having access to major interstate systems to easily access larger cities. While broadband was not explicitly mentioned in the survey, as mentioned in the literature review, Kim and Orazem (2016) find that access to has a large impact on location decisions for education and health service firms compared to other industries. Thus, I use the broadband adoption rate as a proxy for broadband infrastructure in each county. For the variable, 1 is equivalent to 20 percent adoption, 2 is equivalent to 40 percent adoption, 3 is equivalent to 60 percent adoption, 4 is equivalent to 80 percent adoption, and 5 is equivalent to 100 percent adoption. These data are from Form 477, Federal Communications Commission, 2012.

The three remaining community capitals may have less direct impacts on provider retention, but may have indirect relevance. In regards to cultural capital, Pender et al. (2014) explains that cultural capital includes the dynamics of who we know and feed comfortable with, what heritage is valued, and the ability to collaborate across races, ethnicities, and generations. The importance of cultural capital may be especially relevant to international medical graduates who received part of their training outside of the United States. International medical graduates are more likely to practice in primary care specialties and in rural areas (Ranasinghe, 2015). My proxy for cultural capital is share of the population who speaks a language other than English in their home, calculated from the Census Bureau's American Community Survey, using 2019-13 5-year estimates. Intellectual capital may speak to a community’s innovative potential. Could providers who locate in communities with a culture of innovation and problem solving find comforting similarities to the university communities and research hospitals where they previously trained? To measure intellectual capital, I include the rate of patents per capita for each county in 2013. Financial capital, important for entrepreneurship (Conroy, Low and Weiler, 2017), may aid in retention due to providers' ability to access loans for starting their own practice. My financial capital variable is deposits per capita, a reflection of the amount of financial assets a county has to support lending. This 
variable is widely used as a proxy for county-level financial capital availability (Low, Henderson \& Weiler, 2005; Goetz and Rupasingha, 2009).

\section{Model}

To summarize, I regress the probability of whether or not a provider has ever seriously considered moving and practicing in a different location $(\mathrm{Y})$ on the cumulative distribution function of my four vectors of variables including my individual-level control variables, county control variables, Rural Wealth Creation variables, and the important factors for retention variables from Survey Question 24. Below are both the theoretical and reduced form equations for the model. Equation 1 provides the theoretical equation for the probit model that shows the model predicts the probability that the dependent variable (Y) will be one, or in this case "yes," based on the cumulative distribution function $(\Phi)$ of a set of explanatory variables $\left(\beta_{0}+\beta_{1} X\right)$. Equation 2 provides a reduced form of the equation with each of the four vectors being predictors of the dependent variable (Y).

Equation 1: Probit Model Regression Equation

$$
P(Y=1 \mid X)=\Phi\left(\beta_{0}+\beta_{1} X\right)
$$

\section{Equation 2: Reduced Form Equation}

$$
\begin{gathered}
Y=\beta_{0}+\beta_{1} \text { Provider Demographics and History }+\beta_{2} \text { County level Wealth Indicators } \\
+\beta_{3} \text { County Control Variables }+\beta_{4} \text { Important Factors for Retention ) }
\end{gathered}
$$

These four vectors of variables, the demographic vector, the county control vector, Rural Wealth Creation vector, and the important factors vector, create a long list of potential test variables for my model. To identify which of the variables are significant to the model, I run an initial unrestricted model and use Wald testing to test the joint significance of any variables with a p-value of less than 0.20 . For testing joint significance, the Wald test null hypothesis is that the parameters for multiple variables are 0 , meaning they have no effect on the outcome variable. If the p-value for the Wald test is large, I can safely drop the variables from the model and rerun a restricted model with less variables. Finally, there exists 
potential for endogeneity in the Question 24 factors. Due to the nature of the survey, I was unable to identify appropriate instrumental variables for the model. I chose instead to use Lewbel's (2012) model for calculating endogenous regressors, described in more detail below.

\section{Lewbel Approach}

My model may be endogenous. Some unobserved factors, like the current pay the provider received compared to pay they could receive elsewhere when they considered leaving, may be correlated with both the Q24 variables like importance of a good financial package and the fact that they considered leaving. Due to this endogeneity, my third model uses a modified instrumental variable approach. I was not able to identify traditional instrumental variables that correlated with the endogenous Question 24 variables but not correlated with the error term.

Lewbel (2012) introduced an approach that identifies the effects of an endogenous explanatory variable without excluding instrumental variables from the second-stage regression. In ordinary two stage least squares regressions, the first stage regression includes an instrumental variable that is related to the endogenous explanatory variable but not the dependent variable. The instrumental variable is used to predict the coefficients for the explanatory variables in the first stage. However, in the second stage the estimated coefficients for the endogenous variables are used and the instrumental variable is dropped. Instead of identifying instrumental variables, Lewbel's approach relies on the heteroskedasticity in the first-stage regression by creating instrumental variables that are the product of the demeaned value of the explanatory variable and the residual of the regression to predict the endogenous explanatory variables. He uses an assumption that the product of the error terms in the first-stage and second-stage regressions is uncorrelated with at least some or all of the of the explanatory variables. He reasons that we can use these pseudo-instrumental variables due to the common assumption that the correlation between errors in the

first and second stage regression is due to a common unobserved factor in both error terms, as long as the common factor does not have a variance associated with the explanatory variables. I test the Lewbel 
instruments for overidentification, weak identification and under-identification, to ensure there is sufficient heteroskedasticity in the first state regression.

\section{Standard Error Estimation and Survey Weights}

Data for this analysis are from a stratified sample, accordingly standard error estimation has been modified and survey weights have been applied. To best estimate the model, I use jackknife resampling to estimate standard errors. Jackknife standard errors are calculated by systematically calculating the standard error over and over leaving out one observation at a time and then finding the average of all calculations.

Because total responses varied across regions and communities, survey weights are applied to all models. Three communities had over twenty respondents, 31 communities had between 10 and 20 respondents, and the remainder had less than 10. As mentioned before, the region with the greatest number of respondents was the Upper Midwest with 566 responses, followed by the Southern Great Plains with 231 and the Mississippi Delta with 130. Due to a varying number of responses across communities and the survey regions, weights for both the 150 communities in the sample and weights for the region are included. Each response received a weight ranging from 3.37 to 51.88. Both the jackknife standard error estimation and survey weights were calculated by a statistician at the Iowa State Center for Survey Statistics and Methodology. 


\section{CHAPTER 6: RESULTS}

I begin my analysis by estimating first the base model or Model 1, which uses only the provider demographics and familial characteristics variables. To identify any multicollinearity within the model, I first conduct a variance inflation factor test for all variables, found in Table 9. Only two variables have a variance inflation factor of over 2.00, $N P / P A / M W$ and physician. It makes sense that these variables are multicollinear because they are binary variables created for each of the provider types (Remember that dentist is our omitted condition). Despite having VIFs of over 2.00, the VIF for both variables is still relatively low at 3.57 for $N P / P A / M W$ and 2.78 for physician so I choose to leave them in the analysis.

Table 9: Variance Inflation Factors for Model 1 Variables

\begin{tabular}{|l|l|l|}
\hline Variable & VIF & 1/VIF \\
\hline NP/PA/MW & 3.57 & 0.280044 \\
\hline Physician & 2.78 & 0.359864 \\
\hline Owner & 1.95 & 0.512694 \\
\hline Log_age & 1.76 & 0.568722 \\
\hline Female & 1.63 & 0.614249 \\
\hline Kids & 1.54 & 0.647527 \\
\hline Log_hoursworked & 1.37 & 0.729518 \\
\hline Ruraltrain & 1.30 & 0.772154 \\
\hline Livedbefore & 1.22 & 0.816709 \\
\hline Prural & 1.17 & 0.858104 \\
\hline Commute & 1.16 & 0.858677 \\
\hline Volunteer & 1.15 & 0.868775 \\
\hline Underrepresented_minority & 1.09 & 0.916544 \\
\hline Oncall & 1.08 & 0.922541 \\
\hline Leadership & 1.08 & 0.926747 \\
\hline Coverage & 1.06 & 0.940138 \\
\hline Married & 1.06 & 0.941159 \\
\hline Mean VIF & 1.53 & \\
\hline & &
\end{tabular}

I estimate the base regression using a probit model with the specified survey weights and jackknife standard error estimation. I then compute my marginal effects. Marginal can be found in Table 10 (Appendix B contains the complete regression results for all models including coefficients). Due to various providers responding to a different range of questions than others, I lose close to 100 observations from my analysis. However, I still maintain over 89 percent of my total observations. Variables with 
statistical significance $(\mathrm{p}<0.1)$ include owner, log_hoursworked, oncall, and volunteer. Owner and volunteer have negative coefficients meaning they decrease the likelihood of a provider's likelihood to consider leaving, while log_hoursworked and oncall have positive coefficients meaning they increase a provider's likelihood to consider leaving. These results are consistent with expectations that providers that work high weekly hours and feel that they have unacceptable on call responsibilities would be more likely to consider leaving. Conversely, providers who own their practice might be less likely to relocate due to the financial capital and time invested in starting a practice, and providers who volunteer in their community are more likely to establish social capital and integrate within their community.

To this base model I add the Question 24 factors as variables, and then I subsequently add the county level variables. The regression with Question 24 factors included (Model 2) captures provider perceptions of the importance of various community capitals on their decision to stay. The regression that also includes the county level variables (Model 3) strengthens these perceptions by providing a realistic picture of the community capitals available in their respective counties. Coefficients and marginal effects for Model 2 and 3 are reported in Appendix B but not included in the body of the text due to the long list of insignificant variables.

Models 1, 2 and 3 contain statistically significant regression coefficients, but the model may be over specified due to the large number of variables. To eliminate redundant or unnecessary variables, I run a Wald joint significance test of forty-one variables with a p-value of greater than 0.25 , and the Wald test reports a p-value of 0.32 . The relatively high $\mathrm{p}$-value allows me to accept the null hypothesis that all the variables are simultaneously equal to zero, allowing me to eliminate them from the model. 


\begin{tabular}{|c|c|}
\hline VARIABLES & $\begin{array}{c}(2) \\
\text { Marginal } \\
\text { effects }\end{array}$ \\
\hline nppamw & $\begin{array}{c}-0.040 \\
(0.088)\end{array}$ \\
\hline physician & $\begin{array}{l}-0.111 \\
(0.087)\end{array}$ \\
\hline owner & $\begin{array}{c}-0.164 * * \\
(0.065)\end{array}$ \\
\hline female & $\begin{array}{c}0.026 \\
(0.049)\end{array}$ \\
\hline log_age & $\begin{array}{c}0.017 \\
(0.114)\end{array}$ \\
\hline log_hoursworked & $\begin{array}{c}0.296 * * * \\
(0.078)\end{array}$ \\
\hline kids & $\begin{array}{c}0.030 \\
(0.020)\end{array}$ \\
\hline married & $\begin{array}{c}-0.069 \\
(0.070)\end{array}$ \\
\hline underrepresented_minority & $\begin{array}{c}0.000 \\
(0.077)\end{array}$ \\
\hline ruraltrain & $\begin{array}{c}0.045 \\
(0.0489)\end{array}$ \\
\hline prural & $\begin{array}{l}-0.019 \\
(0.023)\end{array}$ \\
\hline livedbefore & $\begin{array}{c}0.023 \\
(0.056)\end{array}$ \\
\hline commute & $\begin{array}{c}0.011 \\
(0.014)\end{array}$ \\
\hline oncall & $\begin{array}{c}0.275^{* * * *} \\
(0.089)\end{array}$ \\
\hline coverage & $\begin{array}{c}-0.109 \\
(0.068)\end{array}$ \\
\hline volunteer & $\begin{array}{c}-0.168 * * * \\
(0.056)\end{array}$ \\
\hline leadership & $\begin{array}{c}0.003 \\
(0.044)\end{array}$ \\
\hline Pseudo R2 & 0.0948 \\
\hline Observations & 833 \\
\hline
\end{tabular}

Standard errors in parentheses $* * * \mathrm{p}<0.01, * * \mathrm{p}<0.05, * \mathrm{p}<0.1$ 
After eliminating the jointly insignificant variables, I run a new, restricted model with only the remaining variables (Model 4). Table 11 includes the variance inflation factors for the remaining variables. All variables have a variance inflation factor of less than 2. After refining the variables, many of my previously insignificant variables gain significance and my pseudo-R squared rises from 0.09 to 0.15 indicating a better fit model. Table 12 contains the marginal effects for the restricted model. Like the initial base model, owner, log_hoursworked, oncall, and volunteer are significant. However, from the provider demographics and familial characteristics variables I gain significance for the variables kids, ruraltrain, and provider_rurality. The marginal effect for kids is positive, meaning having more children at home increases a provider's likelihood of considering leaving. This result may be a reflection of the importance providers place on making sure their children have good quality of life and access to opportunities. Ruraltrain has a positive marginal effect as well, meaning providers who have done a residency, internship, or externship in a rural place are more likely to consider leaving. At first thought, this result seems perplexing, but the willingness to consider leaving could be a result of being comfortable with practicing in a wide range of practice locations that comes from receiving diverse training. Lastly, provider_rurality has a negative marginal effect on a provider's willingness to leave meaning that if a provider was raised in a predominantly rural area, they are less likely to consider leaving their current location. This result is a little more intuitive because providers who are familiar with the specific challenges associated with rural areas may be less likely to consider leaving once practicing.

Only two county-level variables survived the Wald test - the share of the population with a bachelor's degree or higher and the share of the county area in water. Only the share of the population with a bachelor's degree or higher was significant in the restricted model. It is important to note that the number of unique observations for the county-level variables was far less than the number of respondents. Despite having over 900 provider responses, these providers only represented 115 counties, meaning each county-level variable only had 115 unique observations. Because of this, the county-level variables were less likely to have a statistically significant effect on the provider's likelihood to consider leaving. The 
two county-level variables that remain, however, are telling of the importance of human capital and natural capital to provider retention. Interestingly, the share of the population with a bachelor's degree or higher had a positive marginal effect on a provider's likelihood to consider leaving. This result could be explained by higher educated areas having more access to other opportunities, improving provider mobility.

From the comprehensive list of Question 24 factors, only seven out of twenty-three remained after the Wald test, and all factors that remained after the Wald test were significant in the restricted model. Family is settled here and I don't want to uproot them, my spouse or partner has a good job or career, size of town, natural amenities, good professional contacts and collegiality in the medical community, good financial package and reasonable workload were all statistically significant in Model 4 $(\mathrm{p}<0.01)$. These Question 24 factor effects are harder to interpret due to the phrasing of the question and categorization of the responses. Question 24 asked how important each of the reasons were for continuing to work in the community. Questions were included in the model as categorical levels with 5 being very important and 1 being not important. Family is settled, size of town, good professional contacts, and reasonable workload had a negative marginal effect on provider's likelihood to consider moving. This means that the more important a provider ranked these factors, the less likely the provider was to consider leaving the community. Conversely, spouse has a good job, natural amenities, and reasonable workload had positive marginal effects meaning the more important a provider ranked these factors, the less likely the provider was to consider leaving the community. 
Table 11: Model 4 and 5 Variance Inflation Factors

\begin{tabular}{|l|l|l|}
\hline Variable & VIF & 1/VIF \\
\hline Reasonable workload & 1.80 & 0.55 \\
\hline Good financial package & 1.73 & 0.58 \\
\hline Your family is settled there; don't want to uproot them & 1.62 & 0.62 \\
\hline Size of the town & 1.55 & 0.65 \\
\hline $\begin{array}{l}\text { Good professional contacts and collegiality in the medical } \\
\text { community }\end{array}$ & 1.45 & 0.69 \\
\hline Your spouse or partner has a good job/career & 1.34 & 0.74 \\
\hline Natural amenities (climate, scenery, lakes/rivers/ocean, etc.) & 1.32 & 0.76 \\
\hline Owner & 1.23 & 0.81 \\
\hline Ruraltrain & 1.19 & 0.84 \\
\hline Volunteer & 1.19 & 0.84 \\
\hline Kids & 1.13 & 0.88 \\
\hline Log_hoursworked & 1.12 & 0.89 \\
\hline Provider_rurality & 1.07 & 0.93 \\
\hline Oncall & 1.05 & 0.95 \\
\hline Perwaterarea & 1.03 & 0.97 \\
\hline Bachelorsplus13 & 1.03 & 0.97 \\
\hline Mean VIF & 1.30 & \\
\hline
\end{tabular}

Despite the statistical strength of the variables in the restricted model, concern still exists regarding the endogeneity caused by simultaneity between variables. To address this, we use Lewbel's (2012) method of using the heteroskedasticity in the first-stage regression as instrumental variables to predict the endogenous explanatory variables. My final model that uses Lewbel's methods (Model 5) has similar results to the restricted probit model. The results of the Lewbel model are also reported in Table 12. All but one previously significant variable remains, as well as share of the county area in water becoming statistically significant. Signs remain the same for marginal effects of the provider demographics and familial characteristics variables. Share of the population with at least a bachelor's degree remains negative like the restricted probit model and share of the county area in water becomes marginally significant with a negative marginal effect. This result is consistent with expectations since Pender et al. (2012) highlighted the importance of natural amenities to Rural Wealth Creation and McGranahan (1999) found water area to be positively related to population and employment growth. It makes sense that providers in counties with more bodies of water were less likely to consider moving due to the access to natural amenities and recreation. Results for the Question 24 factors are similar with only 
good professional contacts losing statistical significance and good financial package switching from a positive marginal effect to a negative.

I also calculate a under-identification test using a Kleibergen-Paap rk Langrange Multiplier statistic. The p-value for my under-identification test is 0.77 meaning I cannot reject the null that the model is under-identified. Because of the under-identification, the results from the Lewbel (2012) model are not strong but should instead be used to reinforce the findings of the restricted model. All variables except good professional contacts and good financial package kept the same coefficient sign in both models, adding robustness to the findings. The Lewbel model provided an opportunity to address endogeneity in the model and showed that even when controlling for the endogeneity, my results are still robust. 
Table 12: Models 4 and 5 Marginal Effects

\begin{tabular}{|c|c|c|}
\hline VARIABLES & $\begin{array}{c}\text { Restricted } \\
\text { Model } \\
\text { (Model 4) } \\
\text { Marginal } \\
\text { Effects } \\
\end{array}$ & $\begin{array}{c}\text { Lewbel } \\
\text { Model } \\
\text { (Model 5) } \\
\text { Marginal } \\
\text { Effects } \\
\end{array}$ \\
\hline owner & $\begin{array}{c}-0.121 * * \\
(0.046)\end{array}$ & $\begin{array}{c}-0.179 * * * \\
(0.039)\end{array}$ \\
\hline log_hoursworked & $\begin{array}{c}0.226 * * * \\
(0.060)\end{array}$ & $\begin{array}{c}0.264 * * * \\
(0.0346)\end{array}$ \\
\hline kids & $\begin{array}{c}0.040 * * * \\
(0.015)\end{array}$ & $\begin{array}{c}0.040 * * * \\
(0.009)\end{array}$ \\
\hline ruraltrain & $\begin{array}{c}0.110 * * \\
(0.046)\end{array}$ & $\begin{array}{c}0.074 * * \\
(0.031)\end{array}$ \\
\hline Provider_rurality & $\begin{array}{c}-0.041 * \\
(0.022)\end{array}$ & $\begin{array}{c}-0.036 * * \\
(0.014)\end{array}$ \\
\hline oncall & $\begin{array}{l}0.167 * \\
(0.089)\end{array}$ & $\begin{array}{c}0.215^{* * * *} \\
(0.046)\end{array}$ \\
\hline volunteer & $\begin{array}{c}-0.099 * \\
(0.052)\end{array}$ & $\begin{array}{c}-0.113 * * * \\
(0.036)\end{array}$ \\
\hline (a) family is settled & $\begin{array}{c}-0.056^{* * *} * \\
(0.018)\end{array}$ & $\begin{array}{c}-0.046 * * \\
(0.021)\end{array}$ \\
\hline (b) spouse or partner has a good career & $\begin{array}{c}0.0258 * \\
(0.014)\end{array}$ & $\begin{array}{c}0.059 * * * \\
(0.022)\end{array}$ \\
\hline (f) size of town & $\begin{array}{c}-0.072 * * * \\
(0.022)\end{array}$ & $\begin{array}{c}-0.114 * * * \\
(0.026)\end{array}$ \\
\hline (h) natural amenities & $\begin{array}{c}0.034 * * \\
(0.016)\end{array}$ & $\begin{array}{c}0.097 * * * \\
(0.027)\end{array}$ \\
\hline (s) good professional contacts & $\begin{array}{c}-0.042 * * \\
(0.020)\end{array}$ & $\begin{array}{c}0.018 \\
(0.027)\end{array}$ \\
\hline (v) good financial package & $\begin{array}{l}0.044 * \\
(0.022)\end{array}$ & $\begin{array}{c}-0.062 * * * \\
(0.024)\end{array}$ \\
\hline (w) reasonable workload & $\begin{array}{c}-0.058 * * \\
(0.0286)\end{array}$ & $\begin{array}{l}-0.032 \\
(0.029)\end{array}$ \\
\hline bachelorsplus13 & $\begin{array}{c}0.009 * * * \\
(0.003)\end{array}$ & $\begin{array}{c}0.007 * * * \\
(0.002)\end{array}$ \\
\hline perwaterarea & $\begin{array}{l}-0.002 \\
(0.003)\end{array}$ & $\begin{array}{c}-0.003 * \\
(0.001)\end{array}$ \\
\hline Pseudo R2 & 0.1548 & 0.101 \\
\hline Observations & 836 & 836 \\
\hline $\begin{array}{l}\text { Standard errors in parentheses } \\
\quad * * * \mathrm{p}<0.01, * * \mathrm{p}<0.05, * \mathrm{p}<0.1\end{array}$ & & \\
\hline
\end{tabular}




\section{Hypothesis Test Results and Discussion}

I find a combination of provider characteristics and workplace and community attributes impact a provider's likelihood to consider leaving their community. In regards to my first hypothesis regarding the impacts of community on provider retention, while many of my county-level wealth indicators did not impact providers' likelihood to consider leaving, the importance of social capital arose indirectly through other variables. One of the most obvious indicators of the importance of social capital was through the volunteer variable. In all regressions, providers who indicated they had volunteered in their community were less likely to consider leaving. The effect of being a volunteer ranged from a 9 to 16 percent decrease in the likelihood to consider leaving. This result is consistent with findings from Stenger et al. (2008) and Hancock et al. (2009) who both discuss the importance of community involvement to retention. Furthermore, Hancock et al. (2009) discusses providers' desire for familiarity and a sense of place in their community. By volunteering, providers meet and form relationships with others in their community and may begin to recognize the community as their own. Furthermore, three of the Question 24 factors relate well to social capital - family is settled here, size of town, and good professional contacts all had negative effects on a provider's likelihood of considering leaving. This can be interpreted as the higher a provider ranked the importance of these three variables to their decision to continue working in the community, the less likely they were to consider leaving. If a provider feels their family is settled in a community and has integrated and established a sense of place, they may be less likely to consider uprooting their family. Similarly, if a provider has chosen a town large enough to develop many close relationships, it may impact their decision to leave. The same may be said for having good professional contacts. Providers who feel close to their coworkers and other peoples may be less likely to be willing to give up the established social capital in the community they are located in and start over somewhere else.

In regards to workplace characteristics, two themes arose as important - monetary compensation and work-related stress. The importance of a good financial package was statistically significant in both the restricted and Lewbel model. However, the effect of the factor was positive in the restricted model 
and negative in the Lewbel model. It is difficult to interpret the results of these variables because the survey did not collect specific salaries for the provider respondents, and even if salary information was available for the respondents, it would be difficult to compare to other opportunities outside the community. Additionally, the importance of financial package may be the result of reverse causality if providers who are considering leaving are doing so with the hopes of obtaining a better financial package. What is more obvious is the effect of work-related stress and work-life balance on provider retention. Having unacceptable on-call responsibilities increased a provider's likelihood to consider leaving by between 16 and 30 percent. Furthermore, increasing a provider's weekly hours by 8 hours, increased their likelihood to consider leaving by around 20 percent. $^{5}$ Both these results are intuitive and reflect the idea that overworked providers may be more likely to consider leaving. However, what is not so intuitive is the effect of having school age children. While it may seem that having children would decrease a provider's likelihood of considering moving due to not wanting to uproot their family, having more children increased the likelihood to consider leaving. This may be related to work-life balance and provider's feeling they could work less hours and being more present for their families in other locations. Nonetheless, like Cutchin et al. (1994) and Stenger et al. (2008) point out, not feeling overworked and having access to relief coverage may promote rural provider retention.

In addition to the opportunity to obtain better work-balance in another role or location, providers may be more likely to relocate if they have access to a greater quantity of opportunities nearby. This reasoning could explain the positive effect of being located in a county with a higher share of the population with a bachelor's degree or greater. Providers in highly educated counties may have more opportunities for health care professionals, so they may be more aware of opportunities nearby. Similarly, providers who have been trained in a rural setting may be more confident about taking other opportunities

\footnotetext{
${ }^{5}$ A one unit increase above the average number of weekly hours worked (43.6) on the log scale translates to 51.4 weekly hours.
} 
in other rural areas. Providers with spouses who have good jobs or careers might also be more willing to relocate due to opportunities for their spouse.

Hypothesis three sought to assess the impact of entrepreneurship on provider retention. When a provider opens and maintains a practice in a place, he or she invests in physical capital in the form of equipment and office or clinic space and social capital in the form of establishing relationships with patients and employees in a specific location. For all regressions, my ownership variable had a significant negative marginal effect on a provider's likelihood to consider leaving ranging from 12 to 18 percent. Dixit (1989) found that a firm's entry and exit decisions are based on the decision to suffer the sunk cost of closing an existing practice weighed against the entry cost of starting a new practice elsewhere. Providers who choose to sell their practice may gain back some of the physical capital investment in equipment and buildings through monetary payout. They may even sell their customer base for monetary value. However, the existing customers may not feel that the purchasing provider provides the same level of care, and the selling provider may lose value or experience sunk cost in the form of his established relationships with patients. Regardless of the value of the sunk cost, providers face uncertainty when considering selling their practices and may be motivated to "stick out" their current situation instead of facing the uncertainty of potential loss on their investment that comes with selling their practice.

\section{Robustness Checks}

Deciding between a probit model and logit model is often a matter of discipline. For this regression, I have chosen to use a probit model because of its consistent use in econometric models. As a robustness check, I compare the unrestricted model as both a probit and a logit and find all variables to have coefficients with similar signs and statistical significance, making my results robust across models. Furthermore, it may be argued that variables within my model may be dependent upon other included variables.

As mentioned in my results, ruraltrain has a somewhat surprising positive coefficient. To better understand potential underlying causes of the positive effect of rural training on a provider's likelihood to 
consider moving, I look at the interaction between my ruraltrain variable and the fromstate variable that captures providers who graduated high school from the state they currently work in. My reasoning for including this interaction is that providers who are from the state where they now practice may be attempting to locate back in their home community if not already there. When I include my interaction term, I find it to be statistically insignificant, suggesting the interaction between ruraltrain and fromstate is not correlated with my dependent variable.

Similarly, I assess the impact of provider rurality, provider_rurality, and rural training, ruraltrain, to see if a similar situation occurs. This interaction term is also insignificant. Similarly, including both the water area variable and the Question 24 factor that captures the importance of natural amenities to continuing to work in the community could be redundant if the responses to whether or not natural amenities are important to continuing to work in the community are reflective of whether or not a community has natural amenities. I test these variables with an interaction term as well and find it to be insignificant.

Lastly, in all models the natural log of weekly hours worked is significant and has a large marginal effect ranging from 0.22 to 0.29 . If the responses to number of weekly hours worked had many large outliers, it could impact the effects of the variable. I rerun the restricted and Lewbel model with an unlogged weekly hours variable but I cap the variable at sixty hours a week, i.e., if a provider responded with 77 hours his/her value would be replaced with 60 . After running the regression, my weekly hours variable is still significant $(\mathrm{p}<0.01)$ and has a marginal effect of 0.006 . This is interpreted as for every additional weekly hour, a provider's likelihood to consider leaving increases by 0.6 percent. Since the mean of this capped variable is 42.6 hours, I interpret this as a provider working $42.6+10$ hours per week being 6 percent more likely to consider leaving. 


\section{CHAPTER 7: POLICY IMPLICATIONS AND CONCLUSION}

In summary, this thesis expanded the body of knowledge regarding retention of rural health care providers. Using a combination of personal information, survey responses, and county-level data, I identified potential policy-relevant incentives for providers to remain in rural community and potential stressors that may encourage them to consider leaving.

My hypotheses centered on three components of long-term retention: developing social capital, satisfaction with the workplace, and engaging in entrepreneurship. Medical educators, rural communities, and policymakers alike may benefit from these results as they seek to address the challenges of rural health disparities. Statistics aside, it is notable that no individual-level demographic characteristics are significant. Although statistics say that we cannot interpret non-existent results, it is important to note that factors like gender, race and age are absent from my analysis. These results raise the question that demographic factors may not be as pertinent to long term provider retention.

The results of my analysis most clearly illustrated the effects of stress on provider retention. Working more hours, having more kids, and having unacceptable on-call responsibilities all contributed to the likelihood of considering leaving. A more marginally significant result was the importance of having a reasonable workload expressed by the providers in the survey. All four of these variables hit on the importance of work-life balance for rural healthcare providers. Policy makers and rural communities may benefit from fostering regional cooperation to access more providers or invest in multiple providers to prevent burnout of existing physicians. Furthermore, in regards to the negative impacts of having more children, providing access to childcare may help with the work-life stress.

There is potential for provider's number of children to proxy for satisfaction with local schools. In the analysis of the key informant interviews (Pender et al., under review), schools were viewed as both a positive and a negative to provider recruitment and retention. Key informants were proud of the quality of the schools and the opportunities provided to rural students. Good schools were one of the most cited beneficial community assets for recruitment and retention of providers by the key informants. However, 
key informants realized that the diversity of schools or opportunities were less than in urban areas. Unfortunately, the survey data did not ask the health care providers specifically about the importance of schools or the quality of schools. Seventy percent of providers did say that schools were important to their decision to locate within a community, but no questions captured the satisfaction with the local schools. However, the importance of schools in recruitment and retention of professionals may be identified in other literature. Using a survey of rural manufacturers, McGranahan (1998) found that quality of schools was important in attracting managers and professionals to an area and Conte et al.'s (1992) qualitative summary specifically addressed the issue of rural schools for providers' children.

The effects of stress may be further amplified when providers are aware of opportunities elsewhere. Three of the variables in my analysis may be related to a provider's awareness of other opportunities and his or her willingness to consider them. Surprisingly, having rural training in the form of an internship, externship, or residency had a positive effect on a provider's likelihood to consider leaving. This may be the result of access to information. If providers learned of other opportunities in rural areas during training, they may be more likely to consider them once they begin careers.

Another somewhat less intuitive variable is the percent of the population with a bachelor's degree or greater. Despite having a small marginal effect (between 0.6 and 1.2 percent), the share of the population with high levels of education has a positive effect on providers' likelihood to consider leaving. This effect could be the result of providers who live in areas with high education levels being in close proximity to other opportunities that utilize their training.

Two of the Question 24 factors also seem to reflect the idea that the pull of other opportunities may increase a provider's likelihood to consider leaving. Both the importance of "good financial package" and "spouse or partner has a good career" had a marginally significant positive effect on a provider's likelihood to consider leaving. Providers who are aware of other opportunities that have better salaries for themselves or their spouse may be more likely to consider leaving when those opportunities are presented. While willingness to consider leaving based on other opportunities is outside the control of 
both the communities and workplaces of providers, these may be things to consider when working towards long-term retention. Having transparency and awareness of the market and maintaining competitive opportunities may aid in retention.

Some of the most policy relevant findings resulting from this analysis focus on the importance of social capital. Providers who owned their own practice were between eight and sixteen percent less likely to consider leaving. Providers who volunteered in the community were between five and fifteen percent less likely to consider leaving. Providers who invest both social and financial capital in their practices may be less willing to leave due to the sunk costs incurred from procuring office space equipment and developing rapport with a patient base. Additionally, providers who have invested the time and resources into the community in which they live and work may be less likely to leave due to the bonds they have formed and the reluctance to start over somewhere else. In sum, making sure that a provider and his or her family feels connected to the community can aid in satisfaction with a practice location. Establishing social capital for new providers without a previous history in the community may be considered bridging social capital due to providers' unfamiliarity with the community and vice versa. However, as pointed out by Putnam, bridging social capital and establishing "weak" ties with those who have previously moved in different social circles may be more valuable than the "strong" ties that exist within the community.

In regards to factors important to continuing to work in the community, ranking "good professional contacts" and "family is settled" as important had a negative effect on providers' likelihood to consider leaving. The importance of a one's family being settled had between a four and eight percent decrease on the likelihood to consider leaving. This result could be interpreted as providers who have families and are focused on integrating those families into the communities where they work are less likely to consider uprooting them. Similarly, providers who felt that good professional contacts were important to continuing to work in the community were less likely to consider leaving. This could mean that providers who feel supported by other health care professionals both within or outside their community have greater satisfaction with the current situation. However, it is not clear whether or not the 
professional contacts are based locally or in other areas. What is clear is that providers who feel less isolated and have work-related relationships are more content in their roles.

It is noteworthy that my analysis included two variables that proxied for natural amenities and their effect on providers' likelihood to consider leaving. Providers who ranked natural amenities as important to a decision to continue working in the community were more likely to consider leaving, potentially out of dissatisfaction with the lack of natural amenities in the community. Moreover, although only marginally significant in only the Lewbel (2012) model regression, the share of county land in water area had a small negative effect on providers' likelihood to consider leaving. These results may speak to the importance of capitalizing on natural amenities when possible. However, many rural areas may not have natural capital to take advantage of when recruiting health care providers. Instead, it may be more beneficial to focus on bonding and bridging social capital in these communities.

Lastly, some variables from the analysis are not easily interpreted due to survey design. Attempting to interpret the effect of how important a certain factor is to a providers' likelihood to consider leaving is difficult, especially when the factor is not clearly a positive or a negative factor. The importance of the "size of town" was strongly significant in both the restricted and Lewbel (2012) model. However, it is impossible to tell whether a provider feels that size of town is important because they live in a small or large town when the survey does not ask the provider if they feel the town is too big, too small or what they feel is the preferred size of town.

The goal of this thesis was to investigate factors within providers' history, workplace, and community that promote health care provider retention in rural areas. Using provider responses to a USDA Economic Research Service regional survey, I conducted probit model regressions to identify the effects of personal information, survey responses and county level data on providers' likelihood to consider moving and practicing in another location. My results show the importance of establishing social capital and maintaining an acceptable work-life balance on long-term provider retention. Furthermore, results exhibited the effects of the pull of other opportunities on providers' likelihood to consider leaving. 
These results are consistent with the literature that emphasizes the importance of integration and establishing social capital for providers and feeling satisfied with workplace conditions. They are somewhat unique, however, in that they do not speak to the demographic characteristics of providers who choose to practice rural long term. The effects of entrepreneurship are noteworthy due to much of the existing literature not addressing the effects of practice-ownership on provider retention. By committing financial and social capital to build and maintain a practice, providers may be less likely to consider leaving due to the incurred sunk cost. All of these results add to the existing body of literature that seeks to understand why physicians choose rural, and more importantly, why they chose to stay rural.

This analysis is not without flaws. It is important to note that the dependent variable is a hypothetical question. The binary dependent variable reflects whether or not the provider has considered moving and practicing in a different location. It does not capture providers who acted on the decision to move and practice elsewhere. Future studies may benefit from looking comparatively at providers who remain and providers who have left the community. Furthermore, the number of communities represented by the providers who responded to the survey was small and created challenges in assessing how community-level assets impact provider retention at a quantitative level. To better capture the impacts of Rural Wealth Creation on provider retention, a larger number of unique geographies may be beneficial. 


\section{REFERENCES}

Agency for Healthcare Research and Quality. (2016). 2015 National Healthcare Quality and Disparities Report and 5th Anniversary Update on the National Quality Strategy (AHRQ Pub. No. 16-0015). https://archive.ahrq.gov/research/findings/nhqrdr/nhqdr15/2015nhqdr.pdf

American Hospital Association. (2019). Fact Sheet: Telehealth.

Arrow, K. J., Dasgupta, P., Goulder, L. H., Mumford, K. J., \& Oleson, K. (2012). Sustainability and the measurement of wealth. Environment and Development Economics, 17(3), 317-353.

Banfield, E. (1961). Political Influence. Routledge. New York.

Befort, C. A., Nazir, N., \& Perri, M. G. (2012). Prevalence of obesity among adults from rural and urban areas of the United States: Findings from NHANES (2005-2008). The Journal of Rural Health: 28(4), 392-397. PubMed. https://doi.org/10.1111/j.1748-0361.2012.00411.x

Bourdieu, P. (1986). The Forms of Capital. In Handbook of Theory and Research for the Sociology of Education (pp. 241-258). Greenwood Publishing. Westport, CT.

Bradshaw, T., \& Blakely, E. (1999). What are "Third-Wave” State Economic Development Efforts? From Incentives to Industrial Policy. Economic Development Quarterly, 13, 229-244.

Brusie, C. (2020, December 7). Survey of Healthcare Workers Reveals High Levels of Burnout, Stress, \& Thoughts of Leaving Their Jobs. Berxi Resources. https://www.berxi.com/resources/articles/stateof-healthcare-workers-survey/

Cameron, P. J., Este, D. C., \& Worthington, C. A. (2010). Physician retention in rural Alberta: Key community factors. Canadian Journal of Public Health = Revue Canadienne de Sante Publique, 101(1), 79-82. https://doi.org/10.1007/BF03405568

Chen, Y., \& Weber, B. (2012). Federal Policy, Rural Community Growth, and Wealth Creation: The Impact of the Federal Forest Policy and Rural Development Spending in the Pacific Northwest. 
American Journal of Agricultural Economics, 94(2), 542-548.

https://doi.org/10.1093/ajae/aar065

Chipp, C., Dewane, S., Brems, C., Johnson, M. E., Warner, T. D., \& Roberts, L. W. (2011). “If only someone had told me...": Lessons from rural providers. The Journal of Rural Health. 27(1), 122130. PubMed. https://doi.org/10.1111/j.1748-0361.2010.00314.x

Conroy, T., \& Deller, S. C. (2020). Regional Level Social Capital and Business Survival Rates. Review of Regional Studies, 50(2), 230-259.

Conroy, T., Low, S. A., \& Weiler, S. (2017). Fueling job engines: Impacts of small business loans on establishment births in metropolitan and nonmetro counties. Contemporary Economic Policy, 35(3), 578-595. https://doi.org/10.1111/coep.12214

Conte, S., Imershein, A., \& Magill, M. (1992). Rural community and physician perspectives on resource factors affecting physician retention. The Journal of Rural Health, 8(3), 185-196. https://doi.org/10.1111/j.1748-0361.1992.tb00351.x

Craft, S. N. (2017). The Evolution of Advanced Practice Providers in Rural Settings [Historical Paper]. American College of Medical Practice Executives. https://www.mgma.com/MGMA/media/files/fellowship\%20papers/The-Evolution-of-AdvancedPractice-Providers-in-Rural-Settings_1.pdf?ext=.pdf

Cromartie, J., Dobis, E. A., Krumel, T. P., McGranahan, D., \& Pender, J. (2020). Rural America at a Glance, 2020 Edition USDA Economic Research Service. Economic Information Bulletin 221.

Cromartie, J., \& Vilorio, D. (2019, February 15). Rural Population Trends. Amber Waves. USDA Economic Research Service. https://www.ers.usda.gov/amber-waves/2019/february/ruralpopulationtrends/\#: :text=The\%20decline\%20in\%20U.S.\%20rural,0.1\%20percent $\% 2$ C\%20adding\%2033\% 
2C000\%20people.\&text=Rural\%20net $\% 20$ migration $\% 20$ increased $\% 20$ from,essentially $\% 20$ zero $\% 20 \mathrm{in} \% 202016 \% 2 \mathrm{D} 17$.

Cutchin, M. P. (1997). Physician retention in rural communities: The perspective of experiential place integration. Health \& Place, 3(1), 25-41. https://doi.org/10.1016/S1353-8292(96)00033-0

Cutchin, M. P., Norton, J. C., Quan, M. M., Bolt, D., Hughes, S., \& Lindeman, B. (1994). To Stay or Not to Stay: Issues in Rural Primary Care Physician Retention in Eastern Kentucky. The Journal of Rural Health, 10(4), 273-278. https://doi.org/10.1111/j.1748-0361.1994.tb00241.x

Daniels, Z. M., VanLeit, B. J., Skipper, B. J., Sanders, M. L., \& Rhyne, R. L. (2007). Factors in recruiting and retaining health professionals for rural practice. The Journal of Rural Health, 23(1), 62-71. https://doi.org/10.1111/j.1748-0361.2006.00069.x

Deller, S. C. (2014). Strategies for rural wealth creation: A progression of thinking through ideas and concepts. In Rural Wealth Creation. Routledge.

Deller, S. C., \& Deller, M. A. (2010). Rural Crime and Social Capital. Growth and Change, 41(2), 221275. https://doi.org/10.1111/j.1468-2257.2010.00526.x

Deller, S. C., Tsai, T.-H., Marcouiller, D. W., \& Donald B. K. English. (2001). The Role of Amenities and Quality of Life in Rural Economic Growth. American Journal of Agricultural Economics, 83(2), 352-365. JSTOR.

Deller, S., \& Whitacre, B. (2019). Broadband's relationship to rural housing values. Papers in Regional Science, 98(5), 2135-2156. https://doi.org/10.1111/pirs.12450

Dixit, A. (1989). Entry and Exit Decisions under Uncertainty. Journal of Political Economy, 97(3), 620638. JSTOR.

Dobis, E. A., \& McGranahan, D. (2021, February 1). Rural Residents Appear to be More Vulnerable to Serious Infection or Death From Coronavirus COVID-19. Amber Waves. 
https://www.ers.usda.gov/amber-waves/2021/february/rural-residents-appear-to-be-more-

vulnerable-to-serious-infection-or-death-from-coronavirus-covid-19/

Doeksen, G. A., Johnson, T., Biard-Holmes, D., \& Schott, V. (1998). A Healthy Health Sector is Crucial for Community Economic Development. The Journal of Rural Health, 14(1), 66-72. https://doi.org/10.1111/j.1748-0361.1998.tb00864.x

Doeksen, G. A., St. Clair, C. F., \& Eilrich, F. C. (2012). The Economic Impact of a Critical Access Hospital on a Rural Community [Research Study]. National Center for Rural Health Works.

Ellsbury, K. E., Baldwin, L.-M., Johnson, K. E., Runyan, S. J., \& Hart, L. G. (2002). Gender-related factors in the recruitment of physicians to the rural Northwest. The Journal of the American Board of Family Practice, 15(5), 391.

Emery, M., \& Flora, C. (2006). Spiraling-Up: Mapping Community Transformation with Community Capitals Framework. Community Development, 37(1), 19-35. https://doi.org/10.1080/15575330609490152

Flora, C. B., Flora, J. L., \& Fey, S. (2004). Rural Communities: Legacy and Change (2nd ed.). Westview Press.

Florida, R. (2002). The Rise of the Creative Class. Basic Books. New York.

Frenz, D. (2016, August). The staggering costs of physician turnover. Today's Hospitalist. https://www.todayshospitalist.com/staggering-costs-physician-turnover/

Goetz, S., \& Rupasingha, A. (2009). Determinants of growth in non-farm proprietor densities in the US, 1990-2000. Small Business Economics, 32(4), 425-438.

Hancock, C., Steinbach, A., Nesbitt, T. S., Adler, S. R., \& Auerswald, C. L. (2009). Why doctors choose small towns: A developmental model of rural physician recruitment and retention. Social Science \& Medicine, 69(9), 1368-1376. https://doi.org/10.1016/j.socscimed.2009.08.002 
Hedegaard, H., Miniño, A. M., \& Warner, M. (2019). Urban-rural Differences in Drug Overdose Death Rates, by Sex, Age, and Type of Drugs Involved, 2017 (NCHS Data Brief No. 345; pp. 1-8). U.S. Department of Health and Human Services.

Helland, L. C., Westfall, J. M., Camargo, C. A., Rogers, J., \& Ginde, A. A. (2010). Motivations and Barriers for Recruitment of New Emergency Medicine Residency Graduates to Rural Emergency Departments. Annals of Emergency Medicine, 56(6), 668-673.e1. https://doi.org/10.1016/j.annemergmed.2010.06.561

Henderson, J., \& Low, S. (2006). Obesity: America's economic epidemic. Main Street Economist. Federal Reserve Bank of Kansas City, Center for the Study of Rural America, Issue 2.

Henry, L. R., \& Hooker, R. S. (2007). Retention of Physician Assistants in Rural Health Clinics. The Journal of Rural Health, 23(3), 207-214. https://doi.org/10.1111/j.1748-0361.2007.00092.x

Hoffer, D., \& Levy, M. (2010). Measuring Community Wealth. Ford Foundation. http://www. yellowwood. org/wealthcreation

Holmes, G. M., \& Fraher, E. P. (2017). Developing Physician Migration Estimates for Workforce Models. Health Services Research, 52(S1), 529-545. https://doi.org/10.1111/1475-6773.12656

Holmes, G. M., Slifkin, R. T., Randolph, R. K., \& Poley, S. (2006). The effect of rural hospital closures on community economic health. Health Services Research, 41(2), 467-485. PubMed. https://doi.org/10.1111/j.1475-6773.2005.00497.x

Hughes, D. (2019). The Role of Community in Midwestern General Surgeons' Practice Location Decisions. University of Kansas.

Hustedde, C., Paladine, H. L., Wendling, A., Prasad, R., Sola, O., Bjorkman, S., \& Phillips, J. (2018). Women in rural family medicine: A qualitative exploration of practice attributes that promote physician satisfaction. Rural and Remote Health, 18(2), 4355. https://doi.org/10.22605/RRH4355 
Ivey-Stephenson, A. Z., Crosby, A. E., Jack, S. P. D., Haileyesus, T., \& Kresnow-Sedacca, M. (2017). Suicide Trends Among and Within Urbanization Levels by Sex, Race/Ethnicity, Age Group, and Mechanism of Death—United States, 2001-2015 (66(No. SS-18); Morbidity and Mortality Weekly Report: Surveillance Summaries, pp. 1-16). http://dx.doi.org/10.15585/mmwr.ss6618a1

Johnson, K. M., \& Lichter, D. T. (2019). Rural Depopulation: Growth and Decline Processes over the Past Century. Rural Sociology, 84(1), 3-27. https://doi.org/10.1111/ruso.12266

Kefalas, M., \& Carr, P. J. (2009). Hollowing Out the Middle: The Rural Brain Drain and What it Means for America.

Kim, Y., \& Orazem, P. F. (2017). Broadband Internet and New Firm Location Decisions in Rural Areas. American Journal of Agricultural Economics, 99(1), aaw082. https://doi.org/10.1093/ajae/aaw082

Kolko, J. (2012). Broadband and local growth. Journal of Urban Economics, 71(1), 100-113. https://doi.org/10.1016/j.jue.2011.07.004

Kura, R. (2020, November 5). In midst of coronavirus pandemic, rural America desperately needs more doctors like me. USA Today. https://www.usatoday.com/story/opinion/voices/2020/11/05/ruralamerica-covid-19-exacerbating-doctor-and-hospital-bed-shortages/6160363002/

Kushins, E., Heard, H., \& Weber, J. (2017). Disruptive innovation in rural American healthcare: The physician assistant practice. International Journal of Pharmaceutical and Healthcare Marketing, 11. https://doi.org/10.1108/IJPHM-10-2016-0056

Levitt, S. D., \& Poterba, J. M. (1999). Congressional distributive politics and state economic performance. Public Choice, 99(1), 185-216. https://doi.org/10.1023/A:1018341713887 
Lewbel, A. (2012). Using Heteroscedasticity to Identify and Estimate Mismeasured and Endogenous Regressor Models. Journal of Business \& Economic Statistics, 30(1), 67-80. https://doi.org/10.1080/07350015.2012.643126

Lindsay, S. (2007). Gender Differences in Rural and Urban Practice Location Among Mid-level Health Care Providers. The Journal of Rural Health, 23(1), 72-76. https://doi.org/10.1111/j.1748$\underline{0361.2006 .00070 . x}$

Low, S. A. (2005). Regional Asset Indicators: Bank Deposit Depth and Evolution. Main Street Economist. Federal Reserve Bank of Kansas City, Center for the Study of Rural America, Issue 4.

Low, S. A., Bass, M., Thilmany, D., \& Castillo, M. (2020). Local Foods Go Downstream: Exploring the Spatial Factors Driving U.S. Food Manufacturing. Applied Economic Perspectives and Policy, n/a(n/a). https://doi.org/10.1002/aepp.13046

Lutfiyya, M., Shah, K., Johnson, M., Bales, R., Cha, I., McGrath, C., Serpa, L., \& Lipsky, M. (2008). Adolescent daily cigarette smoking: Is rural residency a risk factor? Rural and Remote Health, 81(1), 875. https://doi.org/www.rrh.org.au/journal/article/875

Marre, A. (2017). Rural Education at a Glance, 2017 Edition (Economic Information Bulletin No. 171; Rural Education at a Glance, p. 6). USDA Economic Research Service.

Mayo, E., \& Matthews, M. (2006). Spousal perspectives on factors influencing recruitment and retention of rural family physicians. Canadian Journal of Rural Medicine, 11(4), 271-276.

McGranahan, D. (1999). Natural amenities drive rural population change (Issue 33955). United States Department of Agriculture, Economic Research Service. https://EconPapers.repec.org/RePEc:ags:uerser:33955

McGranahan, D. A. (1998). Local Problems Facing Manufacturers (Agriculture Information Bulletin No. 736-03; Rural Manufacturing Study). USDA Economic Research Service. 
McGranahan, D., \& Wojan, T. (2007). Recasting the Creative Class to Examine Growth Processes in Rural and Urban Counties. Regional Studies, 41, 197-216. https://doi.org/10.1080/00343400600928285

Miller, C., Pender, J., \& Hertz, T. (2017). Employment Spillover Effects of Rural Inpatient Healthcare Facilities (Economic Research Report No. 241). USDA Economic Research Service.

Morris, F. (n.d.). “Toxic Individualism”: Pandemic Politics Driving Health Care Workers From Small Towns. https://www.npr.org/2020/12/28/950861977/toxic-individualism-pandemic-politicsdriving-health-care-workers-from-small-tow?utm_source=pocket-newtab

Negrusa, S., \& Taplin, C. (2016, June 22). Retention Rates: NHSC vs non-NHSC Providers. National Advisory Council for the National Health Service Corps Meeting. https://nhsc.hrsa.gov/sites/default/files/NHSC/NACNHSC/Meetings/advisory-council-meetingJune-2016-nhsc-provider-retention-rates.pdf

Niebuhr, A. (2010). Migration and innovation: Does cultural diversity matter for regional R\&D activity? Papers in Regional Science, 89(3), 563-585. https://doi.org/10.1111/j.1435-5957.2009.00271.x

Ottaviano, G. I. P., \& Peri, G. (2006). The economic value of cultural diversity: Evidence from US cities. Journal of Economic Geography, 6(1), 9-44. https://doi.org/10.1093/jeg/lbi002

Paladine, H. L., Hustedde, C., Wendling, A., Sola, O., Prasad, R., Bjorkman, S., \& Phillips, J. (2020). The role of rural communities in the recruitment and retention of women physicians. Women \& Health, 60(1), 113-122. https://doi.org/10.1080/03630242.2019.1607801

Palmer, W. J. (2020, March 17). The physician shortage: How bad is it, and what's the impact on doctors? https://www.wolterskluwer.com/en/expert-insights/the-physician-shortage-how-bad-isit-and-whats-the-impact-on-doctors 
Pathman, D. E., Konrad, T. R., Dann, R., \& Koch, G. (2004). Retention of primary care physicians in rural health professional shortage areas. American Journal of Public Health, 94(10), 1723-1729. PubMed. https://doi.org/10.2105/ajph.94.10.1723

Pender, J., Hertz, T., Cromartie, J., \& Farrigan, T. (2019). Rural America at a Glance, 2019 Edition (Economic Information Bulletin No. 212; Rural America at a Glance). USDA Economic Research Service. https://www.ers.usda.gov/publications/pub-details/?pubid=95340

Pender, J. L., Weber, B. A., Johnson, T. G., \& Fannin, J. M. (Eds.). (2014). Rural Wealth Creation (1st ed.). Routledge.

Pender, J., Marre, A., \& Reeder, R. (2012). Rural Wealth Creation concepts, strategies, and measures (Economic Research Report No. 131). USDA Economic Research Service.

Psacharopoulos, G., \& Patrinos, H. A. (2002). Returns to investment in education: A further update. The World Bank Policy Research Working Paper Series. https://ideas.repec.org/p/wbk/wbrwps/2881.html

Putnam, R. D. (1993). The Prosperous Community: Social Capital and Public Life. The American Prospect, 13, 35-42.

Putnam, R. D. (2000). Bowling Alone: The Collapse and Revival of American Community. Simon \& Schuster.

Ranasinghe, P. D. (2015). International Medical Graduates in the US Physician Workforce. The Journal of the American Osteopathic Association, 115(4), 236-241. https://doi.org/10.7556/jaoa.2015.047

Renner, D., Westfall, J., Wilroy, L. A., \& Adit, G. (2010). The influence of loan repayment on rural healthcare provider recruitment and retention in Colorado. Rural and Remote Health, 10. www.rrh.org.au/journal/article/1605 
Rephann, T., \& Isserman, A. (1994). New highways as economic development tools: An evaluation using quasi-experimental matching methods. Regional Science and Urban Economics, 24(6), 723-751. https://doi.org/10.1016/0166-0462(94)90009-4

Roberts, M. E., Doogan, N. J., Kurti, A. N., Redner, R., Gaalema, D. E., Stanton, C. A., White, T. J., \& Higgins, S. T. (2016). Rural tobacco use across the United States: How rural and urban areas differ, broken down by census regions and divisions. Health \& Place, 39, 153-159. PubMed. https://doi.org/10.1016/j.healthplace.2016.04.001

Rupasingha, A., \& Goetz, S. (2007). Social and political forces as determinants of poverty: A spatial analysis. Journal of Behavioral and Experimental Economics (Formerly The Journal of SocioEconomics), 36(4), 650-671.

Rupasingha, A., \& Goetz, S. J. (2013). Self-employment and local economic performance: Evidence from US counties*. Papers in Regional Science, 92(1), 141-161. https://doi.org/10.1111/j.14355957.2011.00396.x

Rupasingha, A., Goetz, S. J., \& Freshwater, D. (2006). The production of social capital in US counties. Essays on Behavioral Economics, 35(1), 83-101. https://doi.org/10.1016/j.socec.2005.11.001

Schmit, T. M., Jablonski, B. B. R., Bonanno, A., \& Johnson, T. G. (2020). Measuring stocks of community wealth and its association with food systems efforts in rural and urban places. Working Paper.

Schmit, T. M., Jablonski, B. B. R., Minner, J., Kay, D., \& Christensen, L. (2017). Rural wealth creation of intellectual capital from urban local food system initiatives: Developing indicators to assess change. Community Development, 48(5), 639-656. https://doi.org/10.1080/15575330.2017.1354042 
Singh, G. K., \& Siahpush, M. (2002). Increasing rural-urban gradients in US suicide mortality, 19701997. American Journal of Public Health, 92(7), 1161-1167. PubMed. https://doi.org/10.2105/ajph.92.7.1161

Smith, A. S., \& Trevelyan, E. (2019). The Older Population in Rural America: 2012-2016 (ACS-41; American Community Survey Reports, pp. 1-21). U.S. Census Bureau.

Stenger, J., Cashman, S. B., \& Savageau, J. A. (2008). The primary care physician workforce in Massachusetts: Implications for the workforce in rural, small town America. The Journal of Rural Health: Official Journal of the American Rural Health Association and the National Rural Health Care Association, 24(4), 375-383. PubMed. https://doi.org/10.1111/j.1748$\underline{0361.2008 .00184 . x}$

Stephens, H. M., \& Partridge, M. D. (2011). Do Entrepreneurs Enhance Economic Growth in Lagging Regions? Growth and Change, 42(4), 431-465. https://doi.org/10.1111/j.14682257.2011.00563.x

Symens Smith, A., \& Trevelyan, E. (2019). The Older Population in Rural America: 2012-2016 (ACS41; American Community Survey Reports). https://www.census.gov/content/dam/Census/library/publications/2019/acs/acs-41.pdf

Thomas, S. R., Holmes, G. M., \& Pink, G. H. (2016). To What Extent do Community Characteristics Explain Differences in Closure among Financially Distressed Rural Hospitals? J Health Care Poor Underserved, 27(4A), 194-203. https://doi.org/10.1353/hpu.2016.0176

UNC Cecil G. Sheps Center for Health Services Research. (n.d.). 180 Rural Hospital Closures: January 2005 - Present (136 since 2010) [Map]. https://www.shepscenter.unc.edu/programsprojects/rural-health/rural-hospital-closures/ 
U.S. Health Resources and Services Administration. (2020). Area Health Resource Files: 2019-2020 County Level Data.

Van Sandt, A., Low, S., Jablonski, B. B. R., \& Weiler, S. (2019). Place-Based Factors and the Performance of Farm-Level Entrepreneurship: A Spatial Interaction Model of Agritourism in the U.S. Review of Regional Studies, 49(3), 428-453.

von Reichert, C., Cromartie, J. B., \& Arthun, R. O. (2014). Impacts of Return Migration on Rural U.S. Communities. Rural Sociology, 79(2), 200-226. https://doi.org/10.1111/ruso.12024

Weber, B., Marre, A., Fisher, M., Gibbs, R., \& Cromartie, J. (2007). Education's Effect on Poverty: The Role of Migration. Review of Agricultural Economics, 29(3), 437-445. JSTOR.

Whitacre, B., Gallardo, R., \& Strover, S. (2014). Does rural broadband impact jobs and income? Evidence from spatial and first-differenced regressions. The Annals of Regional Science, 53, 649-670. https://doi.org/10.1007/s00168-014-0637-x

Wiggins, A. T., Huntington-Moskos, L., Rayens, E. A., Rayens, M. K., Noland, M., Butler, K., \& Hahn, E. J. (2020). Tobacco Use Among Rural and Urban US Middle and High School Students: National Youth Tobacco Survey, 2011-2016. The Journal of Rural Health, 36(1), 48-54. $\underline{\text { https://doi.org/10.1111/jrh.12356 }}$

Wojan, T. R., Dotzel, K. R., \& Low, S. A. (2015). Decomposing regional patenting rates: How the composition factor confounds the rate factor. Regional Studies, Regional Science, 2(1), 535-551. https://doi.org/10.1080/21681376.2015.1095112

Zhao, G., Okoro, C. A., Hsia, J., Garvin, W. S., \& Town, M. (2019). Prevalence of Disability and Disability Types by Urban-Rural County Classification-U.S., 2016. American Journal of Preventive Medicine, 57(6), 749-756. https://doi.org/10.1016/j.amepre.2019.07.022 


\section{APPENDIX A: PROVIDER SURVEY INSTRUMENT}

Bolded variables were used in the thesis analysis.

Variable Names

Case ID of Respondent

CaseID

First Digit $=$ Region

4 = Mississippi Delta Region (Region 1 for Key Informant data)

$5=$ Upper Midwest Region (Region 2 for Key Informant data)

$6=$ Southern Great Plains Region (Region 3 for Key Informant data)

Digits 2-4 = Community identifier

Digits 5-6 = Provider identifier

Completion Status

Status

Survey Mode

Mode

Respondent Type (Physician, Dentist, PA/NP/MW)

np/pa/mw; physician; dentist

Respondent Credentials

Credential

Sample Community

City

Sample State

State

Sample Region

Region

Date Survey was Completed or Received

Date

1. Are you currently working as a health care provider in $[\mathrm{TOWN}]$ ?

$$
1=\text { Yes }
$$

2. Your current role as a health care provider:

$$
\begin{aligned}
& 1=\text { Physician }(\text { MD or DO }) \\
& 2=\text { Dentist } \\
& 3=\text { Physician's Assistant } \\
& 4=\text { Nurse Practitioner } \\
& 5=\text { Midwife }
\end{aligned}
$$


3. Your specialty:

$$
\begin{aligned}
& 0=\text { Missing } \\
& 1=\text { Family Practice, General Practice } \\
& 2=\text { Internal Medicine } \\
& 3=\text { Geriatrics } \\
& 4=\text { Pediatrics } \\
& 5=\text { Other }
\end{aligned}
$$

$$
\{0=\text { Missing }\}
$$

5. Year you began working as a health care professional in this community:

$$
\{0=\text { Missing }\}
$$

6. Location of your medical/dental training:

State (US)

Q6_State

Country

Q6_Country

7. Did you spend any part of your residency, an internship, or externship

ruraltrain in a rural area or a small town? $(<20,000$ pop. $)$

$$
\begin{aligned}
& 0=\text { Missing } \\
& 1=\text { Yes } \\
& 2=\text { No }
\end{aligned}
$$

8. Location where you graduated from high school:

State (US) 
9. Where did you primarily grow up?

$0=$ Missing

$1=$ Farm/ranch, not in a town or city (Includes acreage 3 miles from town)

$2=$ Town of less than 20,000 population

$3=$ City of 20,000 to 100,000 population

$4=$ City/Metropolitan area over 100,000 pop.

$5=$ All (Such as the military)

10. Did you ever live in this community before you began working there?

livedbefore

$$
\begin{aligned}
& 0=\text { Missing } \\
& 1=\text { Yes } \\
& 2=\text { No }
\end{aligned}
$$

11. Where do you live in relationship to this community?

$$
\begin{aligned}
& 0=\text { Missing } \\
& 1=\text { Within city limits } \\
& 2=\text { Within } 2 \text { miles of town } \\
& 3=2 \text { to } 10 \text { miles from town } \\
& 4=10 \text { to } 20 \text { miles from town } \\
& 5=20 \text { or more miles from town }
\end{aligned}
$$

12. Where is your current practice based?

$$
\begin{aligned}
& 0=\text { Missing } \\
& 1=\text { In a hospital } \\
& 2=\text { In a clinic } \\
& 3=\text { In an office setting } \\
& 4=\text { In a retail business setting } \\
& 5=\text { Other: }
\end{aligned}
$$

Other practice base (specified)

$$
\begin{aligned}
& 0=\text { Missing } \\
& 1=\text { Sole owner } \\
& 2=\text { Part-owner } \\
& 3=\text { Employee } \\
& 4=\text { Independent contractor }
\end{aligned}
$$


14. Number of hours you work per week in this community (on average): Log_hourworked (a)

15. Number of hours you work per week in other communities :

Log_hoursworked (b)

$0=$ None

$1=$ One hour or less per week, including intermittent/spotty hours - e.g. $4 \mathrm{hrs} 5 \mathrm{x} / \mathrm{yr}\}$

16. Which best describes your current on-call responsibilities?

oncall

$$
\begin{aligned}
& 0=\text { Missing } \\
& 1=\text { Do not have on-call responsibilities } \\
& 2=\text { Acceptable on-call responsibilities } \\
& 3=\text { Unacceptable on-call responsibilities }
\end{aligned}
$$

17. Do you have adequate professional coverage while you're on vacation?

$$
\begin{aligned}
& 0=\text { Missing } \\
& 1=\text { Yes } \\
& 2=\text { No } \\
& 3=\text { Sometimes/Maybe }
\end{aligned}
$$

18. How did you learn about the opportunity to work in this community? (Circle all that apply.)

$$
\begin{aligned}
& 0=\text { Not Selected } \\
& 1=\text { Selected }
\end{aligned}
$$

Family or friends

Q18_1

Professional colleague

School faculty or placement office

Position announcement

Town representative or organization

19. Was there a specific recruitment effort on the part of town leaders to encourage you to work in this community?

$$
\begin{aligned}
& 0=\text { Missing } \\
& 1=\text { Yes } \\
& 2=\text { No } \\
& 3=\text { Unsure, don't remember }
\end{aligned}
$$

[If No or Unsure, Q20_1-6 = 0]

[If No or Unsure, Q20_1-6=0] 
20. If $\mathrm{Q} 19$ = Yes: What did the recruitment entail? (Circle all that apply)

$$
\begin{aligned}
& 0=\text { Not Selected } \\
& 1=\text { Selected }
\end{aligned}
$$

Information provided by community (e.g., brochures, lists of services, etc.)

Q20_1

Site visit for myself arranged by community

Q20_2

Site visit for my spouse/children arranged by community

Q20_3

Site visit for myself arranged by employer

Q20_4

Site visit for my spouse/children arranged by employer

Q20_5

Other

Other Recruitment (specified)

Q20_6_Other

21. How important to you were each of the following factors in your decision to practice in this community?

$$
\begin{aligned}
& 0=\text { Missing } \\
& 1=\text { Not Important } \\
& 2 \\
& 3=\text { Neutral } \\
& 4 \\
& 5=\text { Very Important }
\end{aligned}
$$

a. Your own familiarity with this area

Q21_a

b. Opportunities for your spouse or partner

Q21_b

c. Relatives or friends are nearby

Q21_c

d. Good place to raise a family

Q21_d

e. Quality of schools

Q21_e

f. Size of the town

Q21_f

g. Recreational opportunities

h. Natural amenities (climate, scenery, lakes/rivers/ocean, etc.)

Q21_g

Q21_h

i. Cultural amenities (local arts, historical sites, cultural events, etc.)

Q21_i

j. Social opportunities (churches, social organizations, etc.)

Q21_j

k. Friendliness of the people

Q21_k

1. Availability of goods and services

Q21_1

m. Low taxes

n. Low cost of living

Q21_m

Q21_n

o. The need for health care providers in the community

Q21_o

p. Recruitment efforts by the community

Q21_p

q. Placement through a program (NHSC, visa waiver, etc.)

Q21_q

r. Quality of medical facilities

Q21_r

s. Quality of the medical community

Q21_S

t. Opportunities for your professional growth/advancement

Q21_t

u. Opportunity to own a practice

Q21_u

v. Good financial package (salary, benefits, loan forgiveness, etc.)

Q21_v

w. Reasonable workload

Q21_W 
22. What is the most important reason why you chose to practice in this community?

[OPEN TEXT]

23. What was the biggest drawback to choosing to practice in this community?

[OPEN TEXT]

24. How important to you are each of the following reasons for continuing to work in this community?

$$
\begin{aligned}
& 0=\text { Missing } \\
& 1=\text { Not Important } \\
& 2 \\
& 3=\text { Neutral } \\
& 4 \\
& 5=\text { Very Important }
\end{aligned}
$$

a. Your family is settled there; don't want to uproot them Q24_a

b. Your spouse or partner has a good job/career $\quad$ Q24_b

c. Relatives or friends are nearby

d. Good place to raise a family

Q24_c

Q24_d

Q24_e

Q24_f

f. Size of the town

Q24_g

Q24_h

Q24_i

h. Natural amenities (climate, scenery, lakes/rivers/ocean, etc.)

Q24_j

j. Your involvement in community activities

k. Friendliness of the people, good friendships

Q24_k

Q24_1

1. Availability of goods and services

Q24_m

m. Low taxes

n. Low cost of living

o. The need for health care providers in the community, having a positive impact

Q24_n through your practice

p. Efforts by the community to encourage you to stay

q. Quality of the medical facilities

Q24_q

Q24_r

r. Quality of the medical community

Q24_s

s. Good professional contacts and collegiality in the medical community

Q24_t

t. Opportunities for your professional growth/advancement

Q24_u

u. Your investment in your practice (patient base, office, equipment, etc.)

Q24_v

v. Good financial package

w. Reasonable workload 

practicing in a different location?

$$
\begin{aligned}
& 0=\text { Missing } \\
& 1=\text { Yes } \\
& 2=\text { No } \quad[\text { IF NO, Q26 and Q27 = blank }]
\end{aligned}
$$

26. IF Q25 = YES: What was the main reason that you considered leaving?

[OPEN TEXT]

27. IF Q25 = YES: What was the main reason that you decided to stay?

[OPEN TEXT]

28. How would you rate the overall availability of health care in this community?

$$
\begin{aligned}
& 0=\text { Missing } \\
& 1=\text { Poor } \\
& 2=\text { Fair } \\
& 3=\text { Good } \\
& 4=\text { Very Good } \\
& 5=\text { Excellent }
\end{aligned}
$$

29. How would you rate the overall quality of health care in this community?

$$
\begin{aligned}
& 0=\text { Missing } \\
& 1=\text { Poor } \\
& 2=\text { Fair } \\
& 3=\text { Good } \\
& 4=\text { Very Good } \\
& 5=\text { Excellent }
\end{aligned}
$$

30. In your opinion, how has the availability of health care services in this community changed over the past 5 years?

$$
\begin{aligned}
& 0=\text { Missing } \\
& 1=\text { Declined a Lot } \\
& 2=\text { Declined a Little } \\
& 3=\text { No Change } \\
& 4=\text { Improved a Little } \\
& 5=\text { Improved a Lot }
\end{aligned}
$$


31. In your opinion, how has the quality of health care services in this community changed over the past 5 years?

$$
\begin{aligned}
& 0=\text { Missing } \\
& 1=\text { Declined a Lot } \\
& 2=\text { Declined a Little } \\
& 3=\text { No Change } \\
& 4=\text { Improved a Little } \\
& 5=\text { Improved a Lot }
\end{aligned}
$$

32. In your opinion, are the changes in the availability of health care in this community due to any of the following reasons?

$$
\begin{aligned}
& 0=\text { Missing } \\
& 1=\text { Yes } \\
& 2=\text { No } \\
& 3=\text { Don't Know }
\end{aligned}
$$

a. Changes in health care facilities or equipment Q32_a

b. Changes in health care professionals $\quad$ Q32_b

c. Changes in health facility administration/ownership Q32_c

d. Changes in government policies/programs $\quad$ Q32_d

e. Changes in the health insurance industry $\quad$ Q32_e

f. Changes in the local economy or business community Q32_f 
33. In your opinion, are the changes in the quality of health care in this community due to any of the following reasons?

$$
\begin{aligned}
& 0=\text { Missing } \\
& 1=\text { Yes } \\
& 2=\text { No } \\
& 3=\text { Don't Know }
\end{aligned}
$$

a. Changes in health care facilities or equipment $\quad$ Q33_a

b. Changes in health care professionals $\quad$ Q33_b

c. Changes in health facility administration/ownership Q33_c

d. Changes in government policies/programs $\quad$ Q33_d

e. Changes in the health insurance industry Q33_e

f. Changes in the local economy or business community Q33_f

34. In the past 5 years, have you ever been involved in the recruitment of other health care professionals to this town?

$$
\begin{aligned}
& 0=\text { Missing } \\
& 1=\text { Yes } \\
& 2=\text { No }
\end{aligned}
$$


35. In the past 5 years, have you ever been involved in an organized effort to encourage other local health care professionals to stay in this town?

$$
\begin{aligned}
& 0=\text { Missing } \\
& 1=\text { Yes } \\
& 2=\text { No }
\end{aligned}
$$

36. In general, what would you say is the most important factor in successfully recruiting or retaining health care providers in this town?

$$
\text { [OPEN TEXT] }
$$

37. In general, what would you say is the greatest difficulty in recruiting or retaining health care providers in this town?

\section{[OPEN TEXT]}

38. How much have you been involved in volunteer activities in this community that are related to health care or promoting healthy lifestyles? (e.g., speaking to local groups on health issues, helping address a local health problem, participating in a community health fair, etc.)

$$
\begin{aligned}
& 0=\text { Missing } \\
& 1=\text { Not at all } \\
& 2=\text { Some } \\
& 3=\text { A lot } \\
& 4=\text { A lot in the early years }- \text { not at all in recent years. }
\end{aligned}
$$

39. How much have you been involved in other volunteer activities in this community volunteer (b) that are not related to health? (E.g., school, charity, sports activities, etc.)

$$
\begin{aligned}
& 0=\text { Missing } \\
& 1=\text { Not at all } \\
& 2=\text { Some } \\
& 3=\text { A lot }
\end{aligned}
$$

40. Do you currently hold a local government leadership position in this community? leadership (a)

$$
\begin{aligned}
& 0=\text { Missing } \\
& 1=\text { Yes } \\
& 2=\text { No }
\end{aligned}
$$


41. Do you currently hold a leadership position in a civic organization in this community?

leadership (b)

$$
\begin{aligned}
& 0=\text { Missing } \\
& 1=\text { Yes } \\
& 2=\text { No }
\end{aligned}
$$

42. How many local organizations or associations do you belong to in this community?

$$
\begin{aligned}
& 0=\text { None } \\
& 1=\text { One or two } \\
& 2=\text { Three to five } \\
& 3=\text { Six to ten } \\
& 4=\text { More than ten }
\end{aligned}
$$

43. How easy is it for someone to get involved in community activities in this town?

$$
\begin{aligned}
& 0=\text { Missing } \\
& 1=\text { Very easy } \\
& 2=\text { Somewhat easy } \\
& 3=\text { Unsure } \\
& 4=\text { Somewhat difficult } \\
& 5=\text { Very difficult }
\end{aligned}
$$

44. What are your professional plans for the next 5 years?

$$
\begin{aligned}
& 0=\text { Missing } \\
& 1=\text { Continue to practice in this community }[\text { IF Q44 =1, 5, or 6, Q45 = blank] } \\
& 2=\text { Move practice to another location } \\
& 3=\text { Change career path in this community } \\
& 4=\text { Change career path in another location } \\
& 5=\text { Retire } \quad \text { [IF Q44 }=1,5, \text { or } 6, \text { Q45 }=\text { blank }] \\
& 6=\text { Other } \quad[\text { IF Q44 }=1,5 \text {, or } 6, \text { Q45 = blank }]
\end{aligned}
$$

Other professional plans (specified) 
46. Your Gender

female

$$
\begin{aligned}
& 1=\text { Male } \\
& 2=\text { Female }
\end{aligned}
$$

47. Your current age

$$
0=\text { Missing }
$$

log_age

48. Your Ethnicity

$$
\begin{aligned}
& 0=\text { Missing } \\
& 1=\text { Hispanic } \\
& 2=\text { Not Hispanic }
\end{aligned}
$$

49. Your race (Circle all that apply.)

$$
\begin{aligned}
& 0=\text { Not Selected } \\
& 1=\text { Selected }
\end{aligned}
$$

White

Black or African American

American Indian or Alaska Native

Asian

Native Hawaiian or Other Pacific Islander

Other

Other race (specified)

\section{underrepresented_minority (a)}

\section{underrepresented_minority (b)}

Q49_1

Q49_2

Q49_3

Q49_4

Q49_5

Q49_6

Q49-6_Other

married

\section{Your current marital status:}

married

$0=$ Missing

$1=$ Married or living as married

$2=$ Divorced or separated

$3=$ Widowed

$4=$ Single never married 
$\underline{\text { Variable Names }}$

51. Your Household (HH) Size:

Number in $\mathrm{HH}$ age 18 or older

Q51Adults

$0=$ Missing

Number in HH under 18 years old

Kids

52. Your household income last year

Q52

$$
\begin{aligned}
& 0=\text { Missing } \\
& 1=\text { Less than } \$ 25,000 \\
& 2=\text { From } \$ 25,000 \text { up to } \$ 50,000 \\
& 3=\text { From } \$ 50,000 \text { up to } \$ 75,000 \\
& 4=\text { From } \$ 75,000 \text { up to } \$ 100,000 \\
& 5=\text { From } \$ 100,000 \text { up to } \$ 150,000 \\
& 6=\$ 150,000 \text { or more }
\end{aligned}
$$

53. Please record any other comments you would like to make regarding your experience as a health care provider in this community.

[OPEN TEXT] 


\section{APPENDIX B: COMPLETE REGRESSION RESULTS FOR ALL FIVE MODELS}

For all models, robust standard errors are in parentheses.

Significance is denoted as $* * * p<0.01, * * p<0.05, * p<0.1$

Table 13: Model 1 (Base model) Coefficients and Marginal Effects

\begin{tabular}{|c|c|c|}
\hline VARIABLES & $\begin{array}{c}\text { (1) } \\
\text { Coefficients } \\
\end{array}$ & $\begin{array}{c}(2) \\
\text { Marginal } \\
\text { effects } \\
\end{array}$ \\
\hline nppamw & $\begin{array}{l}-0.114 \\
(0.248)\end{array}$ & $\begin{array}{l}-0.040 \\
(0.088)\end{array}$ \\
\hline physician & $\begin{array}{l}-0.314 \\
(0.248)\end{array}$ & $\begin{array}{l}-0.111 \\
(0.087)\end{array}$ \\
\hline owner & $\begin{array}{c}-0.463 * * \\
(0.189)\end{array}$ & $\begin{array}{c}-0.164 * * \\
(0.065)\end{array}$ \\
\hline female & $\begin{array}{l}0.0743 \\
(0.138)\end{array}$ & $\begin{array}{c}0.026 \\
(0.049)\end{array}$ \\
\hline log_age & $\begin{array}{l}0.0501 \\
(0.323)\end{array}$ & $\begin{array}{c}0.017 \\
(0.114)\end{array}$ \\
\hline log_hoursworked & $\begin{array}{c}0.838 * * * \\
(0.225)\end{array}$ & $\begin{array}{c}0.296^{* * * *} \\
(0.078)\end{array}$ \\
\hline kids & $\begin{array}{c}0.0860 \\
(0.0575)\end{array}$ & $\begin{array}{c}0.030 \\
(0.020)\end{array}$ \\
\hline married & $\begin{array}{l}-0.196 \\
(0.200)\end{array}$ & $\begin{array}{l}-0.069 \\
(0.070)\end{array}$ \\
\hline underrepresented_minority & $\begin{array}{c}0.000696 \\
(0.217)\end{array}$ & $\begin{array}{c}0.000 \\
(0.077)\end{array}$ \\
\hline ruraltrain & $\begin{array}{c}0.128 \\
(0.139)\end{array}$ & $\begin{array}{c}0.045 \\
(0.0489)\end{array}$ \\
\hline prural & $\begin{array}{l}-0.0548 \\
(0.0664)\end{array}$ & $\begin{array}{l}-0.019 \\
(0.023)\end{array}$ \\
\hline livedbefore & $\begin{array}{l}0.0664 \\
(0.161)\end{array}$ & $\begin{array}{c}0.023 \\
(0.056)\end{array}$ \\
\hline commute & $\begin{array}{c}0.0317 \\
(0.0407)\end{array}$ & $\begin{array}{c}0.011 \\
(0.014)\end{array}$ \\
\hline oncall & $\begin{array}{c}0.777 * * * \\
(0.255)\end{array}$ & $\begin{array}{c}0.275^{* * * *} \\
(0.089)\end{array}$ \\
\hline coverage & $\begin{array}{l}-0.308 \\
(0.195)\end{array}$ & $\begin{array}{l}-0.109 \\
(0.068)\end{array}$ \\
\hline volunteer & $\begin{array}{c}-0.475^{* * * *} \\
(0.161)\end{array}$ & $\begin{array}{c}-0.168 * * * \\
(0.056)\end{array}$ \\
\hline leadership & $\begin{array}{c}0.00838 \\
(0.126)\end{array}$ & $\begin{array}{c}0.003 \\
(0.044)\end{array}$ \\
\hline Constant & $\begin{array}{l}-2.572 \\
(1.650) \\
\end{array}$ & \\
\hline $\begin{array}{l}\text { Pseudo R2 } \\
\text { Observations }\end{array}$ & $\begin{array}{c}0.0948 \\
833\end{array}$ & \\
\hline
\end{tabular}


Table 14: Model 2 Coefficients and Marginal Effects

\begin{tabular}{|c|c|c|c|c|c|}
\hline VARIABLES & Coefficient & $\begin{array}{c}\text { Marginal } \\
\text { effects }\end{array}$ & VARIABLES & Coefficient & $\begin{array}{c}\text { Marginal } \\
\text { effects }\end{array}$ \\
\hline \multirow[t]{2}{*}{ nppamw } & 0.200 & .0624 & Q24_g & -0.146 & -0.046 \\
\hline & $(0.276)$ & $(0.086)$ & & $(0.104)$ & $(0.032)$ \\
\hline \multirow[t]{2}{*}{ physician } & -0.0917 & -0.029 & Q24_h & $0.187^{*}$ & $0.058 *$ \\
\hline & $(0.258)$ & $(0.081)$ & & $(0.102)$ & $(0.031)$ \\
\hline \multirow[t]{2}{*}{ owner } & $-0.359 *$ & $-0.112 *$ & Q24_i & -0.00916 & -0.003 \\
\hline & $(0.210)$ & $(0.065)$ & & $(0.0767)$ & $(0.024)$ \\
\hline \multirow[t]{2}{*}{ female } & 0.180 & 0.056 & $\mathrm{Q} 24 \_\mathrm{j}$ & -0.0906 & -0.028 \\
\hline & $(0.163)$ & $(0.051)$ & & $(0.0796)$ & $(0.025)$ \\
\hline \multirow[t]{2}{*}{ log_age } & 0.302 & 0.094 & Q24_k & -0.0321 & -0.010 \\
\hline & $(0.359)$ & $(0.111)$ & & $(0.0822)$ & $(0.026)$ \\
\hline \multirow[t]{2}{*}{ log_hoursworked } & $0.843 * * *$ & $0.263 * * *$ & Q24_1 & 0.0787 & 0.025 \\
\hline & $(0.257)$ & $(0.079)$ & & $(0.0749)$ & $(0.023)$ \\
\hline \multirow[t]{2}{*}{ kids } & $0.177 * * *$ & $0.055 * * *$ & Q24_m & 0.0502 & 0.016 \\
\hline & $(0.0647)$ & $(0.020)$ & & $(0.0935)$ & $(0.029)$ \\
\hline \multirow[t]{2}{*}{ married } & -0.216 & -0.067 & Q24_n & -0.00485 & -0.002 \\
\hline & $(0.209)$ & $(0.065)$ & & $(0.0997)$ & $(0.031)$ \\
\hline \multirow{2}{*}{$\begin{array}{l}\text { underrepresented_ } \\
\text { minority }\end{array}$} & -0.0224 & -0.006 & Q24_o & -0.00447 & -0.001 \\
\hline & $(0.285)$ & $(0.089)$ & & $(0.0674)$ & $(0.021)$ \\
\hline \multirow[t]{2}{*}{ ruraltrain } & $0.284^{*}$ & $0.089^{*}$ & Q24_p & -0.0108 & -0.003 \\
\hline & $(0.160)$ & $(0.049)$ & & $(0.0619)$ & $(0.020)$ \\
\hline \multirow[t]{2}{*}{ prural } & -0.0752 & -0.024 & Q24_q & -0.167 & -0.052 \\
\hline & $(0.0762)$ & $(0.023)$ & & $(0.137)$ & $(0.043)$ \\
\hline \multirow[t]{2}{*}{ livedbefore } & 0.160 & 0.050 & Q24_r & 0.110 & 0.034 \\
\hline & $(0.158)$ & (0.049) & & $(0.136)$ & $(0.042)$ \\
\hline \multirow[t]{2}{*}{ commute } & -0.0131 & -0.004 & Q24_s & -0.147 & -0.046 \\
\hline & $(0.0484)$ & $(0.015)$ & & $(0.105)$ & $(0.042)$ \\
\hline \multirow[t]{2}{*}{ oncall } & $0.696 * *$ & $0.217 * *$ & Q24_t & 0.0141 & 0.004 \\
\hline & $(0.323)$ & $(0.098)$ & & $(0.0748)$ & $(0.023)$ \\
\hline \multirow[t]{2}{*}{ coverage } & -0.262 & -0.082 & Q24_u & 0.0243 & 0.008 \\
\hline & $(0.232)$ & $(0.072)$ & & $(0.0600)$ & (0.019) \\
\hline \multirow[t]{2}{*}{ volunteer } & -0.308 & -0.096 & Q24_v & $0.150 *$ & $0.047^{*}$ \\
\hline & (0.204) & $(0.063)$ & & $(0.0789)$ & $(0.024)$ \\
\hline \multirow[t]{2}{*}{ leadership } & 0.0567 & 0.018 & Q24_w & $-0.194 *$ & $-0.060 *$ \\
\hline & $(0.156)$ & $(0.048)$ & & $(0.116)$ & $(0.036)$ \\
\hline \multirow[t]{2}{*}{ Q24_a } & -0.113 & -0.035 & umw & $0.502 * * *$ & $0.157 * * *$ \\
\hline & $(0.0725)$ & $(0.022)$ & & $(0.181)$ & $(0.056)$ \\
\hline \multirow[t]{2}{*}{ Q24_b } & $0.0817 *$ & $0.026^{*}$ & sgp & 0.265 & 0.083 \\
\hline & $(0.0481)$ & $(0.015)$ & & $(0.189)$ & $(0.059)$ \\
\hline \multirow[t]{2}{*}{ Q24_c } & -0.0597 & -0.019 & Constant & -2.375 & \\
\hline & $(0.0503)$ & $(0.016)$ & & $(1.865)$ & \\
\hline \multirow[t]{2}{*}{ Q24_d } & 0.0634 & 0.020 & & & \\
\hline & (0.108) & $(0.033)$ & & & \\
\hline \multirow[t]{2}{*}{ Q24_e } & -0.103 & -0.032 & & & \\
\hline & $(0.0937)$ & $(0.029)$ & & & \\
\hline \multirow[t]{2}{*}{ Q24_f } & $-0.196 * *$ & $-0.061 * *$ & & & \\
\hline & $(0.0815)$ & $(0.025)$ & Observations & 775 & \\
\hline
\end{tabular}


Table 15: Model 3 Coefficients and Marginal Effects

\begin{tabular}{|c|c|c|c|c|c|}
\hline VARIABLES & Coefficient & M.E. & VARIABLES & Coefficient & M.E. \\
\hline \multirow[t]{2}{*}{ nppamw } & 0.273 & 0.083 & Q24_m & 0.0452 & 0.014 \\
\hline & $(0.298)$ & $(0.091)$ & & $(0.0948)$ & $(0.029)$ \\
\hline \multirow[t]{2}{*}{ physician } & -0.0451 & -0.013 & Q24_n & 0.00324 & 0.001 \\
\hline & $(0.275)$ & $(0.084)$ & & $(0.103)$ & $(0.032)$ \\
\hline \multirow[t]{2}{*}{ owner } & -0.326 & -0.099 & Q24_o & 0.00944 & 0.003 \\
\hline & $(0.220)$ & $(0.067)$ & & $(0.0738)$ & $(0.023)$ \\
\hline \multirow[t]{2}{*}{ female } & 0.166 & 0.051 & Q24_p & -0.0156 & -0.005 \\
\hline & $(0.174)$ & $(0.053)$ & & $(0.0644)$ & $(0.020)$ \\
\hline \multirow[t]{2}{*}{ log_age } & 0.303 & 0.093 & Q24_q & -0.108 & -0.033 \\
\hline & $(0.384)$ & $(0.117)$ & & $(0.140)$ & $(0.043)$ \\
\hline \multirow[t]{2}{*}{ log_hoursworked } & $0.899 * * *$ & $0.274 * * *$ & Q24_r & 0.0868 & 0.027 \\
\hline & $(0.276)$ & $(0.083)$ & & $(0.146)$ & $(0.044)$ \\
\hline \multirow[t]{2}{*}{ kids } & $0.167 * *$ & $0.051 * *$ & Q24_s & -0.165 & -0.050 \\
\hline & $(0.0679)$ & $(0.020)$ & & $(0.114)$ & $(0.035)$ \\
\hline \multirow[t]{2}{*}{ married } & -0.252 & -0.077 & Q24_t & -0.00215 & -0.001 \\
\hline & $(0.226)$ & $(0.068)$ & & $(0.0823)$ & $(0.025)$ \\
\hline \multirow[t]{2}{*}{ underrep_minority } & 0.0469 & 0.014 & Q24_u & 0.0229 & 0.007 \\
\hline & $(0.297)$ & $(0.091)$ & & $(0.0619)$ & $(0.019)$ \\
\hline \multirow[t]{2}{*}{ ruraltrain } & 0.262 & 0.080 & Q24_v & $0.167 * *$ & $0.051 * *$ \\
\hline & $(0.174)$ & $(0.052)$ & & $(0.0811)$ & $(0.024)$ \\
\hline \multirow[t]{2}{*}{ prural } & -0.0993 & -0.030 & Q24_w & $-0.194 *$ & -0.059 \\
\hline & $(0.0771)$ & $(0.023)$ & & $(0.117)$ & $(0.035)$ \\
\hline \multirow[t]{2}{*}{ livedbefore } & 0.181 & 0.055 & acspop10 & $7.16 \mathrm{e}-06$ & $2.19 \mathrm{e}-06$ \\
\hline & $(0.165)$ & $(0.050)$ & & $(2.23 \mathrm{e}-05)$ & $(6.78 \mathrm{e}-06)$ \\
\hline \multirow[t]{2}{*}{ commute } & -0.0133 & -0.004 & hpsa10 & -0.0338 & -0.010 \\
\hline & $(0.0491)$ & $(0.015)$ & & $(0.195)$ & $(0.060)$ \\
\hline \multirow[t]{2}{*}{ oncall } & $0.677 * *$ & $0.206 * *$ & perpop65plus 13 & 0.0382 & 0.012 \\
\hline & $(0.320)$ & $(0.095)$ & & $(0.0457)$ & $(0.014)$ \\
\hline \multirow[t]{2}{*}{ coverage } & -0.267 & -0.081 & perc_uninsured13 & -0.0156 & -0.005 \\
\hline & $(0.242)$ & $(0.074)$ & & $(0.0411)$ & $(0.013)$ \\
\hline \multirow[t]{2}{*}{ volunteer } & -0.324 & -0.099 & phys_per_100thou_13 & 0.00111 & 0.000 \\
\hline & $(0.215)$ & $(0.065)$ & & $(0.00304)$ & $(0.001)$ \\
\hline leadership & 0.0450 & 0.013 & pci_13 & $4.89 \mathrm{e}-07$ & $1.49 \mathrm{e}-07$ \\
\hline & $(0.175)$ & $(0.053)$ & & $(2.41 \mathrm{e}-05)$ & $(7.36 \mathrm{e}-06)$ \\
\hline Q24_a & $-0.126^{*}$ & -0.038 & sk09 & -0.169 & -0.052 \\
\hline & $(0.0729)$ & $(0.022)$ & & $(0.155)$ & $(0.047)$ \\
\hline Q24_b & 0.0793 & 0.024 & perotherlanguage13 & -0.00732 & -0.002 \\
\hline & $(0.0541)$ & $(0.016)$ & & $(0.0169)$ & $(0.005)$ \\
\hline Q24_c & -0.0584 & -0.018 & bachelorsplus 13 & 0.0284 & 0.009 \\
\hline & $(0.0555)$ & $(0.017)$ & & $(0.0187)$ & $(0.006)$ \\
\hline Q24_d & 0.0794 & 0.024 & eduexpppl_13 & $2.68 \mathrm{e}-05$ & $8.19 \mathrm{e}-06$ \\
\hline & $(0.109)$ & $(0.033)$ & & $(7.18 \mathrm{e}-05)$ & $(0.000)$ \\
\hline Q24_e & -0.115 & -0.035 & patentspc13 & 16.56 & 5.057 \\
\hline & $(0.0999)$ & $(0.030)$ & & $(691.1)$ & $(211.04)$ \\
\hline Q24_f & $-0.208 * *$ & $-0.064 * *$ & depositspc13 & 0.00657 & 0.002 \\
\hline & $(0.0824)$ & $(0.025)$ & & $(0.0184)$ & $(0.006)$ \\
\hline Q24_g & -0.123 & -0.037 & perwaterarea & -0.0124 & -0.004 \\
\hline & $(0.108)$ & $(0.033)$ & & $(0.0100)$ & $(0.003)$ \\
\hline Q24_h & 0.159 & 0.049 & HwyExit & 0.0758 & 0.023 \\
\hline & $(0.114)$ & $(0.034)$ & & $(0.160)$ & $(0.049)$ \\
\hline Q24_i & -0.0364 & -0.011 & bbhsrate2012 & -0.0359 & -0.011 \\
\hline & $(0.0814)$ & $(0.025)$ & & $(0.148)$ & $(0.045)$ \\
\hline Q24_j & -0.0822 & -0.025 & umw & 0.165 & 0.050 \\
\hline & $(0.0819)$ & $(0.025)$ & & $(0.338)$ & $(0.104)$ \\
\hline Q24_k & -0.0158 & -0.005 & sgp & 0.0347 & 0.011 \\
\hline & $(0.0844)$ & $(0.026)$ & & $(0.295)$ & $(0.091)$ \\
\hline Q24_1 & 0.0612 & 0.0187 & Constant & -3.503 & \\
\hline & $(0.0850)$ & $(0.026)$ & & $(2.652)$ & \\
\hline & & & Observations & 763 & \\
\hline
\end{tabular}


Table 16: Model 4 (restricted model) Coefficients and Marginal Effects

\begin{tabular}{|c|c|c|}
\hline VARIABLES & $\begin{array}{c}(1) \\
\text { leaver }\end{array}$ & $\begin{array}{c}(2) \\
\text { Marginal } \\
\text { effects }\end{array}$ \\
\hline owner & $\begin{array}{c}-0.369 * * \\
(0.145)\end{array}$ & $\begin{array}{c}-0.121 * * \\
(0.046)\end{array}$ \\
\hline log_hoursworked & $\begin{array}{c}0.688 * * * \\
(0.186)\end{array}$ & $\begin{array}{c}0.226 * * * \\
(0.060)\end{array}$ \\
\hline kids & $\begin{array}{c}0.123 * * * \\
(0.0462)\end{array}$ & $\begin{array}{c}0.040 * * * \\
(0.015)\end{array}$ \\
\hline ruraltrain & $\begin{array}{c}0.323 * * \\
(0.142)\end{array}$ & $\begin{array}{c}0.110 * * \\
(0.046)\end{array}$ \\
\hline prural & $\begin{array}{l}-0.124 * \\
(0.0686)\end{array}$ & $\begin{array}{c}-0.041 * \\
(0.022)\end{array}$ \\
\hline oncall & $\begin{array}{l}0.510 * \\
(0.277)\end{array}$ & $\begin{array}{c}0.167^{*} \\
(0.089)\end{array}$ \\
\hline volunteer & $\begin{array}{c}-0.283 * \\
(0.160)\end{array}$ & $\begin{array}{c}-0.099 * \\
(0.052)\end{array}$ \\
\hline Q24_a & $\begin{array}{c}-0.172 * * * \\
(0.0568)\end{array}$ & $\begin{array}{c}-0.056 * * * \\
(0.018)\end{array}$ \\
\hline Q24_b & $\begin{array}{l}0.0787 * \\
(0.0427)\end{array}$ & $\begin{array}{c}0.0258 * \\
(0.014)\end{array}$ \\
\hline Q24_f & $\begin{array}{c}-0.219 * * * \\
(0.0698)\end{array}$ & $\begin{array}{c}-0.072 * * * \\
(0.022)\end{array}$ \\
\hline Q24_h & $\begin{array}{l}0.105^{* *} \\
(0.0504)\end{array}$ & $\begin{array}{c}0.034 * * \\
(0.016)\end{array}$ \\
\hline Q24_s & $\begin{array}{c}-0.127 * * \\
(0.0614)\end{array}$ & $\begin{array}{c}-0.042 * * \\
(0.020)\end{array}$ \\
\hline Q24_v & $\begin{array}{c}0.136 * \\
(0.0694)\end{array}$ & $\begin{array}{l}0.044 * \\
(0.022)\end{array}$ \\
\hline Q24_w & $\begin{array}{c}-0.177 * * \\
(0.0885)\end{array}$ & $\begin{array}{c}-0.058 * * \\
(0.0286)\end{array}$ \\
\hline bachelorsplus13 & $\begin{array}{c}0.0271 * * * \\
(0.00852)\end{array}$ & $\begin{array}{c}0.009 * * * \\
(0.003)\end{array}$ \\
\hline perwaterarea & $\begin{array}{l}-0.00492 \\
(0.00935)\end{array}$ & $\begin{array}{l}-0.002 \\
(0.003)\end{array}$ \\
\hline Constant & $\begin{array}{l}-1.452^{*} \\
(0.786)\end{array}$ & \\
\hline Pseudo R2 & 0.1548 & \\
\hline Observations & 836 & \\
\hline
\end{tabular}


Table 17: Model 5 (Lewbel Model) Coefficients

\begin{tabular}{|c|c|}
\hline VARIABLES & Coefficients \\
\hline Q24_a & $\begin{array}{c}-0.0461 * * \\
(0.0208)\end{array}$ \\
\hline Q24_b & $\begin{array}{c}0.0594 * * * \\
(0.0216)\end{array}$ \\
\hline Q24_f & $\begin{array}{c}-0.114 * * * \\
(0.0261)\end{array}$ \\
\hline Q24_h & $\begin{array}{c}0.0972 * * * \\
(0.0267)\end{array}$ \\
\hline Q24_s & $\begin{array}{c}0.0182 \\
(0.0267)\end{array}$ \\
\hline Q24_v & $\begin{array}{c}-0.0623 * * * \\
(0.0240)\end{array}$ \\
\hline Q24_W & $\begin{array}{l}-0.0322 \\
(0.0295)\end{array}$ \\
\hline owner & $\begin{array}{c}-0.179 * * * \\
(0.0395)\end{array}$ \\
\hline lhourswrk & $\begin{array}{c}0.264 * * * \\
(0.0346)\end{array}$ \\
\hline kids & $\begin{array}{c}0.0404 * * * \\
(0.00915)\end{array}$ \\
\hline ruraltrain & $\begin{array}{c}0.0739 * * \\
(0.0311)\end{array}$ \\
\hline prural & $\begin{array}{c}-0.0365 * * \\
(0.0145)\end{array}$ \\
\hline oncall & $\begin{array}{c}0.215 * * * \\
(0.0456)\end{array}$ \\
\hline volunteer & $\begin{array}{c}-0.113 * * * \\
(0.0360)\end{array}$ \\
\hline bachplus13 & $\begin{array}{c}0.00671 * * * \\
(0.00207)\end{array}$ \\
\hline pwater & $\begin{array}{c}-0.00278^{*} \\
(0.00147)\end{array}$ \\
\hline Constant & $\begin{array}{c}-0.186 \\
(0.165) \\
\end{array}$ \\
\hline
\end{tabular}

Observations $\quad 836$

R-squared $\quad 0.101$

Underidentification test (Kleibergen-Paap rk LM statistic) 48.84

p-value: 0.770

Weak identification test (Cragg-Donald Wald F statistic)

1.75

Hansen $\mathrm{J}$ statistic (overidentification test of all instruments) 40.03

p-value: 0.947 